\title{
Metabolic Aspects of Adenosine Functions in the Brain
}

\author{
Mercedes Garcia-Gil ${ }^{1,2 *}$, Marcella Camici ${ }^{3}$, Simone Allegrini ${ }^{3}$, Rossana Pesi ${ }^{3}$ and \\ Maria Grazia Tozzi ${ }^{3}$
}

${ }^{1}$ Department of Biology, Unit of Physiology, University of Pisa, Pisa, Italy, ${ }^{2}$ Interdepartmental Research Center "Nutraceuticals and Food for Health", University of Pisa, Pisa, Italy, ${ }^{3}$ Department of Biology, Unit of Biochemistry, University of Pisa, Pisa, Italy

\section{OPEN ACCESS}

Edited by:

Francisney Pinto Nascimento, Universidade Federal da Integração

Latino-Americana, Brazil

Reviewed by: Carla Denise Bonan, Pontifical Catholic University of Rio

Grande do Sul, Brazil Doo-Sup Choi,

Mayo Clinic College of Medicine and

Science, United States Enric I Canela,

University of Barcelona, Spain

Estefanía Moreno,

University of Barcelona, Spain

*Correspondence:

Mercedes Garcia-Gil mercedes.garcia@unipi.it

Specialty section: This article was submitted to Neuropharmacology,

a section of the journal Frontiers in Pharmacology

Received: 25 February 2021 Accepted: 27 April 2021

Published: 14 May 2021

Citation:

Garcia-Gil M, Camici M, Allegrini S, Pesi $R$ and Tozzi MG (2021) Metabolic Aspects of Adenosine Functions in the Brain.

Front. Pharmacol. 12:672182. doi: 10.3389/fphar.2021.672182
Adenosine, acting both through G-protein coupled adenosine receptors and intracellularly, plays a complex role in multiple physiological and pathophysiological processes by modulating neuronal plasticity, astrocytic activity, learning and memory, motor function, feeding, control of sleep and aging. Adenosine is involved in stroke, epilepsy and neurodegenerative pathologies. Extracellular concentration of adenosine in the brain is tightly regulated. Adenosine may be generated intracellularly in the central nervous system from degradation of AMP or from the hydrolysis of S-adenosyl homocysteine, and then exit via bi-directional nucleoside transporters, or extracellularly by the metabolism of released nucleotides. Inactivation of extracellular adenosine occurs by transport into neurons or neighboring cells, followed by either phosphorylation to AMP by adenosine kinase or deamination to inosine by adenosine deaminase. Modulation of the nucleoside transporters or of the enzymatic activities involved in the metabolism of adenosine, by affecting the levels of this nucleoside and the activity of adenosine receptors, could have a role in the onset or the development of central nervous system disorders, and can also be target of drugs for their treatment. In this review, we focus on the contribution of $5^{\prime}$ nucleotidases, adenosine kinase, adenosine deaminase, AMP deaminase, AMP-activated protein kinase and nucleoside transporters in epilepsy, cognition, and neurodegenerative diseases with a particular attention on amyotrophic lateral sclerosis and Huntington's disease. We include several examples of the involvement of components of the adenosine metabolism in learning and of the possible use of modulators of enzymes involved in adenosine metabolism or nucleoside transporters in the amelioration of cognition deficits.

Keywords: adenosine, 5'-nucleotidases, adenosine deaminase, adenosine kinase, S-adenosylhomocysteine hydrolase, nucleoside transporters, brain, metabolism

\section{INTRODUCTION}

Adenosine regulates multiple physiological and pathophysiological processes, by acting both through G-protein coupled adenosine receptors and intracellularly. It modulates neuronal plasticity (Sebastiao and Ribeiro, 2015), astrocytic activity (Agostinho et al., 2020), learning and memory (Chen, 2014; Simoes et al., 2016; Bannon et al., 2017; Perrier et al., 2019; Temido-Ferreira et al., 2019; Zhang et al., 2020), food intake (Kola, 2008), motor function (Mori, 2020), sleep/wake cycle (Donlea et al., 2017; Lazarus et al., 2019), pain (Vincenzi et al., 2020), immunosupression (Vijayan et al., 2017), proliferation (Jacobson et al., 2019), and aging (Costenla et al., 2011). Adenosine is involved in ischemia and stroke (Williams-Karnesky and Stenzel-Poore, 2009; Melani et al., 2014; PereiraFigueiredo et al., 2021), epilepsy (Boison and Jarvis, 2020; Tescarollo et al., 2020), and 


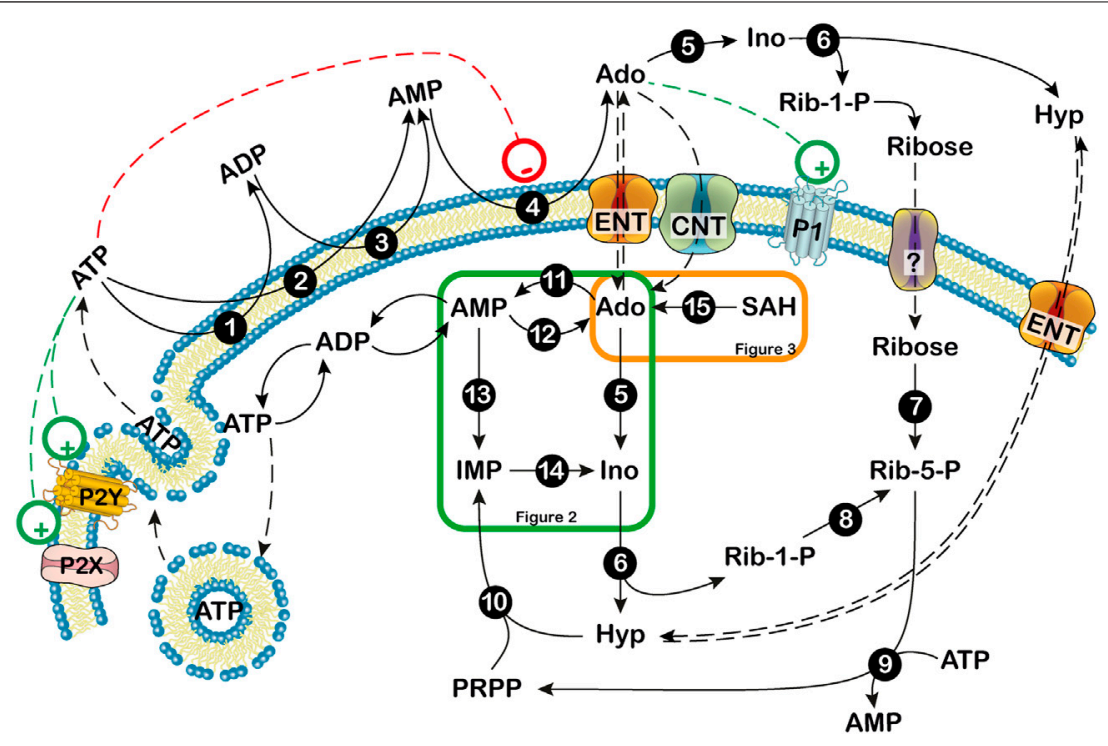

FIGURE 1 | Extra- and intracellular adenosine production. Extracellularly, ATP can be dephosphorylated to AMP by ectonucleoside triphosphate diphosphohydrolase (CD39) or ecto-nucleotide pyrophosphatase/phosphodiesterase. Then, AMP can be dephosphorylated to adenosine by the extracellular $5^{\prime}$-nucleotidase, CD73. Extracellular adenosine can be converted into hypoxanthine (Hyp) and ribose-1 phosphate (Rib-1-P) by the combined action of ectosolic adenosine deaminase and purine nucleoside phosphorylase. Extracellular Rib-1-P might be dephosphorylated by membrane phosphatases and equilibrates with the intracellular ribose through a not yet defined transporter (?). Inside the cell, at low energy charge, adenosine originates mainly from AMP and can be exported or deaminated. When extracellular adenosine generated from ATP breakdown is transported inside the cell, it might be phosphorylated by the low $K_{M}$ ADK or deaminated by the high $K_{M}$ ADA if adenosine reaches high levels. 1,3: ecto-nucleoside triphosphate diphosphohydrolase; 2: ecto-nucleotide pyrophosphatase/phosphodiesterase; 4: ecto-5'nucleotidase; 5: adenosine deaminase; 6: purine nucleoside phosphorylase; 7: ribokinase; 8: phosphoribomutase; 9: 5-phosphoribosyl-1-pyrophosphate synthetase; 10: hypoxanthine guanine phosphoribosyltransferase; 11: adenosine kinase; 12: cytosolic 5' nucleotidase I; 13: AMP deaminase; 14: cytosolic 5' nucleotidase Il; 15: S-adenosylhomocysteine hydrolase. Ado: adenosine; CNT: concentrative nucleoside transporter; ENT: equilibrative nucleoside transporter; Hyp: hypoxanthine; Ino: inosine; P1: purinergic receptor type 1; P2: purinerigic receptor type 2; Rib-1-P: ribose-1-phosphate; Rib-5-P: ribose-5-phosphate. Green and orange boxes indicate that these pathways are described in more details in Figures 2, 3. +: stimulation; -: inhibition.

neurodegenerative pathologies such as Parkinson's disease (PD) (Fredholm and Svenningsson, 2020; Glaser et al., 2020), Alzheimer's disease (AD) (Rahman, 2009; Cunha and Agostinho, 2010; Cellai et al., 2018), amyotrophic lateral sclerosis (ALS) (Ng et al., 2015; Sebastiao et al., 2018), and Huntington's disease (HD) (Lee and Chern, 2014). Extracellular adenosine, interacting with $\mathrm{P} 1$ receptors (A1R, $\mathrm{A} 2 \mathrm{AR}, \mathrm{A} 2 \mathrm{BR}$, and A3R) regulates metabolism through different signaling pathways. In fact, the binding of adenosine to A1R and A3R activates the $G_{i / o}$ family of G-proteins, which inhibits adenylate cyclase, while the binding to A2AR and A2BR, through activation of $\mathrm{G}_{\mathrm{s}}$ protein, stimulates the production of cyclic AMP (Burnstock, 2017), thus contributing to the finetuning of synapses and to the coordination of neuronal circuitry (Agostinho et al., 2020). In neurons and astrocytes, heteromers can be formed by interaction of A1R with A2AR, A2AR with $\mathrm{A} 2 \mathrm{BR}$, and $\mathrm{A} 2 \mathrm{AR}$ with dopamine $\mathrm{D} 2, \mathrm{D} 3$ and $\mathrm{D} 4$ receptors (Guidolin et al., 2020). The interactions between receptors in these complexes modify the signaling and function of the individual receptors and lead to signal integration in the central nervous system. For example, the heteromer A2AR-D2 receptor is found in the striatum where it transforms the dopamine-facilitated inhibition into adenosine-induced activation of adenylate cyclase (Ferré and Ciruela, 2019). Higher order heteroreceptor complexes of A2AR-D2 receptor with either-metabotropic glutamate receptor 5 or Sigma1 receptor have also been described (Borroto-Escuela et al., 2020). It has been hypothesized that heteroreceptors could be involved in learning and memory, including memory associated drug addition and that heteroreceptor complexes could be a target for the treatment of schizophrenia, drug addition, and PD (Borroto-Escuela et al., 2020, 2021; Glaser et al., 2020).

The concentration of extracellular adenosine depends on both intracellular and extracellular purine nucleotide catabolism and on the traffic of the nucleoside across the membrane through specific transporters (Baldwin et al., 2004; Pastor-Anglada and Pérez-Torras, 2018; Camici et al., 2018b). Extracellular adenosine can arise from the degradation of intracellular ATP (Figure 1) (Camici et al., 2018b). At high energy charge, mainly inosine and hypoxanthine are generated by ATP catabolism. In fact, in these conditions, both the cytosolic 5'-nucleotidase II (NT5C2) and AMP deaminase (AMPD) are allosterically activated by ATP (Figure 2) (Ashby and Holmsen, 1983; Tozzi et al., 2013), therefore AMP is deaminated by AMPD into IMP, which is dephosphorylated into inosine by NT5C2. Conversely, at low energy charge, the accumulation of AMP inside the cell, leads to the activation of a specific AMP-activated protein kinase (AMPK), the main regulator of cellular energy homeostasis (Hardie et al., 2012; Rosso et al., 2016; Peixoto et al., 2017; Liu et al., 2020) (Figure 2). The dephosphorylation of AMP by a high 


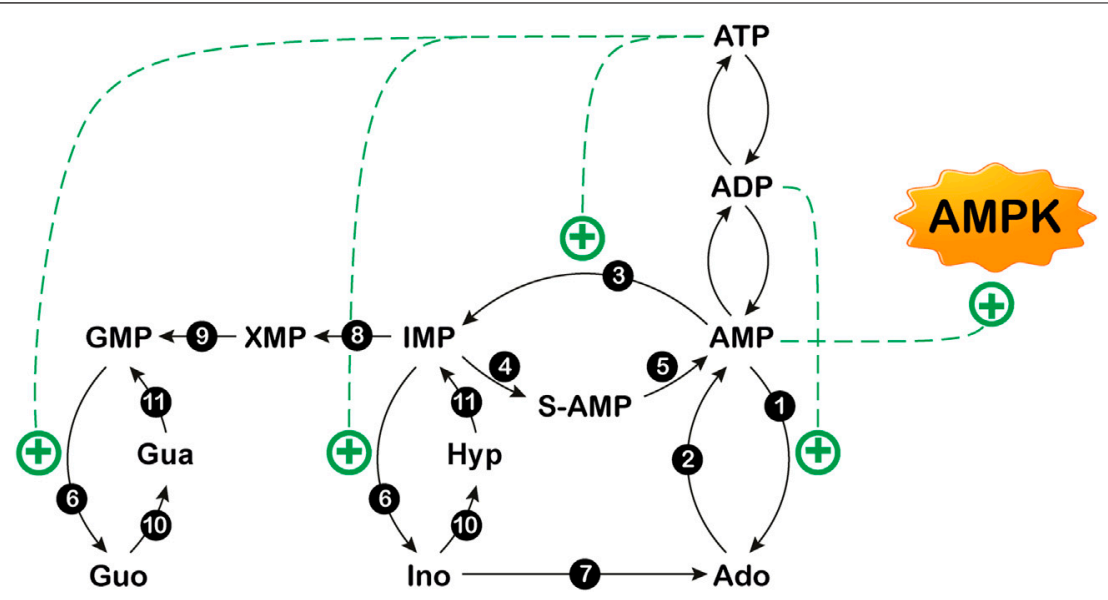

FIGURE 2 | Purine nucleotide cycles. 1: 5'-nucleotidase I; 2: adenosine kinase; 3: AMP deaminase; 4: adenylosuccinate synthase; 5: adenylosuccinate lyase; 6: cytosolic 5'-nucleotidase II; 7: adenosine deaminase; 8: IMP dehydrogenase; 9: GMP synthase; 10: purine nucleoside phosphorylase; 11: hypoxanthine guanine phosphoribosyltransferase. The figure also shows that AMP is an activator of AMP-activated protein kinase (AMPK). Ado: adenosine; Gua: guanine; Guo: guanosine; Hyp: hypoxhanthine; Ino: inosine. S-AMP: succinylAMP. +: stimulation.

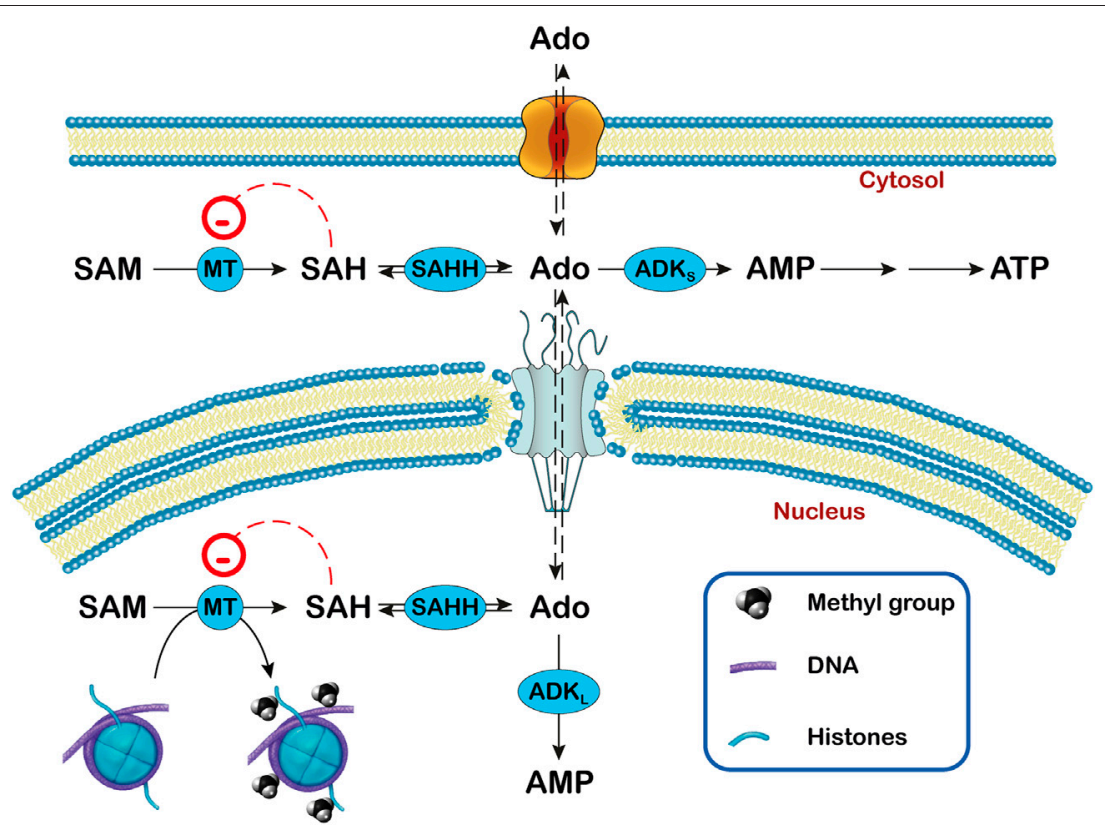

FIGURE 3 | Relationship between adenosine, ADK and transmethylation reactions in subcellular compartments. In the transmethylation reactions catalyzed by methyltransferases (MT), S-adenosylmethionine (SAM) donates the methyl group to various acceptors and is converted to S-adenosylhomocysteine (SAH), which generates adenosine (Ado) by the action of S-adenosylhomocysteine hydrolase (SAHH). In the nucleus, the methyl group can be transferred to DNA and histones. The activity of $A D K\left(A D K_{S}\right.$ in the cytoplasm and $A D K_{L}$ in the nucleus) decreases the concentration of Ado and favors the transmethylation reactions. In this way, $A D K_{L}$ contributes to the DNA methylation in the nucleus.

$\mathrm{K}_{\mathrm{M}}$ AMP-specific 5'-nucleotidase I (NT5C1) which is strongly activated by $\mathrm{ADP}$, leads to increased intracellular adenosine (Skladanowski and Newby, 1990). In such conditions, adenosine might be deaminated, but the $\mathrm{K}_{\mathrm{M}}$ of adenosine deaminase (ADA) for adenosine is sufficiently high (25-150 $\mu \mathrm{M})$ (Ford et al., 2000; Ipata et al., 2011) to favor adenosine increase and exit through nucleoside transporters
(Baldwin et al., 2004). Therefore, the generation of intracellular adenosine and its exportation to the external medium occurs when AMP accumulates, giving the nucleoside the possibility to act as a danger signal, both by interacting with specific receptors on the same cell or on the neighboring cells. Intracellular adenosine can be converted into both AMP, by adenosine kinase $(\mathrm{ADK})$ and inosine, by $\mathrm{ADA}$. In turn, AMP, 
through the sequential action of AMPD and cytosolic NT5C2 is converted into inosine, which, by the action of purine nucleoside phosphorylase (PNP) is transformed into hypoxanthine (Figure 1) (Camici et al., 2018b). Inosine and hypoxanthine can also be transported to the extracellular compartment (Yao et al., 2002). As shown in Figures 1, 3, adenosine can be also generated intracellularly from S-adenosyl homocysteine (SAH) through the action of S-adenosyl homocysteine hydrolase (SAHH) (Garcia-Gil et al., 2018).

ATP can exit the cells through vesicles or through pannexin channels, or can be released by dying cells (Bodin and Burnstock, 2001). The nucleotide can interact with two families of receptors: P2X receptors, which are ion-gated channels displaying neuromodulatory functions, and $\mathrm{P} 2 \mathrm{Y}$ receptors, which are G-protein coupled (Burnstock, 2017). This interaction modulates neuronal firing and mediates neuroinflammation (Rodrigues et al., 2015). Extracellularly, ATP can be dephosphorylated to AMP by ectonucleoside triphosphate diphosphohydrolase (CD39). Then, AMP can be dephosphorylated to adenosine by the extracellular 5'nucleotidase (CD73). Extracellular adenosine can be converted into hypoxanthine and ribose-1 phosphate by the combined action of ectosolic ADA and PNP (Figure 1). In fact, there are several indications that both $\mathrm{ADA}$ and $\mathrm{PNP}$ are present inside the cells and are also released in the extracellular space ensuring a rapid degradation of extracellular adenosine into hypoxanthine, thereby helping to prevent a dangerous accumulation of the nucleoside. This occurrence has also been reported in the brain (Wall et al., 2007; Gracia et al., 2008). Extracellular ribose-1-phosphate might be dephosphorylated by several phosphatases present on the membrane and equilibrates with the intracellular ribose possibly through one member of the family of glucose transporters as demonstrated in Leishmania (Naula et al., 2010).

As a result of the regulation of its metabolism, adenosine does not reach very high concentrations in healthy cells because it is readily metabolized. Hypoxanthine can be salvaged by hypoxanthine-guanine phosphoribosyltransferase (HPRT) into inosine monophosphate (IMP) or can be excreted as uric acid. Ribose- 5- phosphate can be utilized for 5-phosphoribosyl-1pyrophosphate (PRPP) synthesis, and can be used for energy repletion or glucose synthesis (Garcia-Gil et al., 2018). Indeed, adenosine accumulation can impair essential cellular functions. In fact, deficiency of ADA which brings about an accumulation of adenosine and deoxyadenosine is the most common cause of severe combined immunodeficiency (SCID). These purine compounds are detrimental particularly for the immune system and also impair the functionality of the nervous system (Sauer et al., 2017). In this review, we describe the contribution of 5'-nucleotidases, ADK, ADA, AMPD and nucleoside transporters in epilepsy, cognition, and neurodegenerative diseases with a particular attention on serious pathological conditions such as ALS and HD. For a better insight on adenosine receptor expression, function and regulation, the reader is referred to the numerous excellent reviews covering the different aspects of purinergic receptors (Cunha, 2016; Burnstock, 2017).

\section{5'-NUCLEOTIDASES}

NT5C1, which has been mainly studied in skeletal muscle, and NT5C2, which is ubiquitously expressed, are the major cytosolic NT5Cs acting on intracellular nucleotides (Camici et al., 2020). Among purine nucleotides, AMP, with a $\mathrm{K}_{\mathrm{M}}$ in the millimolar range (Hunsucker et al., 2001; Tkacz-Stachowska et al., 2005) is the preferred substrate for $\mathrm{NT5C1}$, while IMP and GMP are better substrates for NT5C2 ( $\mathrm{K}_{\mathrm{M}}$ in the micromolar range) (Tozzi et al., 2013; Pesi et al., 2021), but this enzyme catalyzes also the hydrolysis of the phosphoester bond of AMP (with a $K_{M}$ in the millimolar range) (Tozzi et al., 2013). The intracellular concentrations of IMP, GMP and also AMP depend on the rate of the AMP-IMP-GMP cycles (Figure 2) which in turn depends on NT5C2 activity (Barsotti et al., 2003). In fact, at high energy charge, excess IMP, synthesized by de novo or salvage pathways, is converted to inosine and therefore directed to catabolic pathways, while at low energy charge IMP and AMP accumulate (Pesi et al., 1994; Allegrini et al., 2004; Wallden and Nordlund, 2011; Camici et al., 2018a). NT5C1 has been associated to some autoimmune diseases (Rietveld et al., 2018), while an association has been reported between NT5C2 expression and psychiatric and psychomotor disorders including schizophrenia (Cross-Disorder Group of the Psychiatric Genomics Consortium, 2013; Duarte et al., 2016; Duarte et al., 2019) and hereditary spastic paraplegias (HSP) (Garcia-Gil et al., 2018; Camici et al., 2020). At early stages of AD, NT5C activity is reduced in membranes and cytosol in distinct cortical regions such as the frontal cortex, and only at advanced stages in cytosol in the temporal cortex (Alonso-Andres et al., 2018). Recently, decrease in NT5C2 activity has also been found in the senescenceaccelerated mouse-prone 8 , a model of AD (Sanchez-Melgar et al., 2020).

HSPs comprise a group of genetically heterogeneous neurodegenerative disorders presenting progressive spasticity in the lower limbs (Blackstone, 2018). In addition, skin abnormalities, epilepsy, intellectual disability, deafness, optic atrophy, peripheral neuropathy and ataxia, have been reported in association with autosomal recessive inheritance. Several mutations associated with NT5C2 in HSP type 45 have been described (Novarino et al., 2014; Darvish et al., 2017; Elsaid et al., 2017; Straussberg et al., 2017; Naseer et al., 2020). A splice mutation associated with a substantial reduction in NT5C2 level has been found in two children with severe early spasticity, mild cognitive impairment, and dysgenic and thin corpus callosum (Elsaid et al., 2017), whereas corpus callosum with normal white matter was found in their apparently normal heterozygous brother. Therefore, homozygous alteration in NT5C2 appears to be necessary to produce central white matter developmental defects (Elsaid et al., 2017). A 1954-bp homozygous deletion at the NT5C2 locus involving the entire coding exon 11 was identified in two siblings with HSP and intellectual disability (Darvish et al., 2017). Microcephaly has been found in two cases described by Novarino et al. (2014) and Naseer et al. (2020). The mechanisms underlying the clinical manifestations of NT5C 2 mutations are unknown but it has been reported that $\mathrm{NT} 5 \mathrm{C} 2$ expression is higher during fetal 
development and that, within the adult brain, NT5C2 is enriched in neurons compared to glial cells (Duarte et al., 2019). The same authors have demonstrated that NT5C2 knockdown in human neural stem cells increased the expression and the phosphorylation of the $\alpha$-subunit of AMPK (Duarte et al., 2019). Moreover, studies in Drosophila melanogaster have shown that knockdown of the NT5C2 homologue in neurons is associated with climbing impairment suggesting a role for NT5C2 in motility (Duarte et al., 2019). Furthermore, we demonstrated that transitory NT5C2 silencing in an astrocytoma cell line (ADF) caused apoptosis, while a constitutive silencing increased oxidative metabolism and decreased cell proliferation (Careddu et al., 2008; Pesi et al., 2018). It would be valuable to obtain information on the levels of expression and activity of NT5C2 and the concentration of AMP and ATP in HSP patients, since alterations of their ratio affect AMPK activity, and a continous activation of this enzyme could result in abnormal functioning and development of the nervous system (Pesi et al., 2000; Garcia-Gil et al., 2003; Williams et al., 2011; Domise et al., 2019) (see section AMPK).

In humans, the family of NT5C2 is encoded by five genes (NT5C2, NT5DC1-4). The presence of a nucleotidase domain in NT5DC1-4, allows to hypothesize that these genes code for proteins having 5'-nucleotidase activity, but the enzymatic activity has not been directly measured. Singgih et al. (2021) have recently reported the expression of orthologues of the NT5C2 family in the brain of Drosophila melanogaster and that the neuronal knockdown of two of them resulted in impaired habituation learning. NT5DC2 has also been associated with cognitive ability, bipolar disorder and schizophrenia (Watanabe et al., 2019) while the expression level of $N t 5 d c 3$, has been positively correlated with reversal learning performance in mice (Laughlin et al., 2011).

\section{ECTONUCLEOTIDASES}

Ectonucleotidases control the levels of ATP and its hydrolysis products ADP, AMP and adenosine in the synaptic cleft. The major families of ectonucleotidases are CD39, ecto-nucleotide pyrophosphatase/phosphodiesterases, alkaline phosphatases, and CD73. Adenosine, the final product of ATP extracellular degradation, can be either degraded by extracellular ADA and PNP into hypoxanthine and ribose-1-phosphate, or enter the cell through equilibrative and/or concentrative nucleoside transporters (see below, nucleoside transporters section) (Figure 1). CD73 is inhibited by micromolar concentration of ADP and ATP (Zimmermann, 1992), therefore when ATP is released and accumulates outside the cell, it is hydrolyzed into ADP and AMP and is converted to adenosine only after the disappearance of ATP and ADP. In the basal ganglia, CD73, which generates adenosine from extracellular AMP, colocalizes with A2ARs (Augusto et al., 2013) and the enzyme has been recently demonstrated to act a part in A2AR signaling in both $\mathrm{PD}$ models and patients (Carmo et al., 2019; Meng et al., 2019). CD73-derived adenosine-A2AR signaling is able to modulate microglial immunoresponses and the extension of microglial processes and movement (Meng et al., 2019). Moreover, the reduction of adenosine generated from CD73 decreased microglia-mediated neuroinflammation, increased dopaminergic neuron viability and motor function in a model of PD (Meng et al., 2019). In a model of AD, $\beta$-amyloid increased ATP release and CD73 activity, leading to adenosine generation, activation of A2AR and impairment of synaptic plasticity and memory (Goncalves et al., 2019). The hippocampal astrogliosis observed in mesial temporal lobe epilepsy patients is associated to an increase in expression of A2AR and CD73 (Barros-Barbosa et al., 2016). Finally, in addition to its role in the generation of adenosine, CD73 might participate in the regulation of cell adhesion, migration and differentiation, since CD73 acts as receptor for extracellular matrix molecules including tenascin C, fibronectin and laminin (Sadej et al., 2008).

In many cases neurodegenerative diseases are the consequence of neuroinflammation. In reactive astrocytes, increased CD73 gene expression or increased CD73 activity was reported in ALS (Gandelman et al., 2010), epilepsy (Bonan et al., 2000; Bonan, 2012), ischemia (Braun et al., 1998) and traumatic brain injury (Nedeljkovic et al., 2006; Bjelobaba et al., 2011). Upregulation of CD73 has also been found in glioma (Quezada et al., 2013; Xu et al., 2013), while in a model of multiple sclerosis, upregulation of CD73 and CD39 has been reported in reactive astrocytes and in microglia, respectively (Lavrnja et al., 2015; Jakovljevic et al., 2019). The involvement of ectonucleotidases in the regulation of microglial function, the pathogenesis of infectious diseases in the nervous system and the complex regulation of CD73 at the neurovascular unit during neuroinflammation have been recently reviewed by Nedeljkovic (2019), Alves et al. (2020) and Illes et al. (2020). Altogether these observations suggest that reduction of $\mathrm{CD} 73$ activity, and therefore, adenosine levels, might be a therapeutical tool to decrease neuroinflammation in $\mathrm{PD}$ as well as astrogliosis in mesial temporal lobe epilepsy, and likely, to improve cognition in $\mathrm{AD}$ and PD.

\section{ADENOSINE KINASE}

ADK catalyzes the transfer of the $\gamma$-phosphate from ATP to adenosine, leading to the formation of AMP, and has the capability to regulate both extracellular adenosine and intracellular adenine nucleotide levels. Human ADK consists of two alternatively spliced forms with distinct cellular and subcellular localization. $\mathrm{ADK}$-short $\left(\mathrm{ADK}_{\mathrm{S}}\right)$ is mainly cytoplasmatic and the longer form $\left(\mathrm{ADK}_{\mathrm{L}}\right)$ is nuclear (Cui et al., 2009; Kiese et al., 2016; Boison and Jarvis, 2020). ADK is found mainly in neurons at early stages of development but later it becomes more abundant in astrocytes. The function of the two isoforms appears to be different. Indeed, overexpression of $\mathrm{ADK}_{\mathrm{S}}$ in the brain resulted in spontaneous seizures and increased brain injury after ischemic stroke (Li et al., 2008; Shen et al., 2011). Overexpression of $\mathrm{ADK}_{\mathrm{L}}$ in dorsal forebrain neurons attenuated neural stem cell proliferation (Gebril et al., 2020), while transgenic mice lacking $\mathrm{ADK}_{\mathrm{L}}$ in the dental gyrus showed increased neurogenesis. In addition, $\mathrm{ADK}_{\mathrm{L}}$ might have a more 
prominent role in epigenetic mechanisms requiring transmethylation than $\mathrm{ADK}_{\mathrm{S}}$ (Williams-Karnesky et al., 2013). Methyltransferases catalyze the transfer of methyl groups from the donor S-adenosylmethionine (SAM) to proteins such as histones and DNA yielding S-adenosylhomocysteine (SAH) (Figure 3), whose cleavage into adenosine and homocysteine is catalyzed by $\mathrm{S}$-adenosylhomocysteine hydrolase (SAHH). The removal of adenosine by $\mathrm{ADK}$ favors the transmethylation reactions. When the clearance of adenosine is impaired, the increased levels of SAH inhibit DNA methyltransferases (James et al., 2002) (Figure 3).

Both deficiency and excess of ADK are harmful. ADK deficiency is a very rare inborn error of metabolism, and is characterized by defects in transmethylation reactions associated with developmental delay, hepatic encephalopaties as well as seizures in some individuals (Bjursell et al., 2011; Shakiba et al., 2016; Staufner et al., 2016; Alhusani et al., 2019; Becker et al., 2021). Mutations of ADK or modification of ADK levels have been associated with several diseases (Garcia-Gil et al., 2018), such as stroke (Shen et al., 2011), Rasmussen encephalitis (Luan et al., 2013), focal cortical dysplasia (Luan et al., 2015), epilepsy (Boison, 2016) and gliomas (de Groot et al., 2012; Huang et al., 2015), as well as in cognition deficits (Bjursell et al., 2011; Singer et al., 2012; Sandau et al., 2016; Shakiba et al., 2016; Staufner et al., 2016; Osborne et al., 2018; Kuptanon et al., 2019). Notably, genetic variants of $\mathrm{ADK}$ are associated with posttraumatic epilepsy in humans (Diamond et al., 2015). Dysfunction of adenosine signaling, which is common in neurological disorders, might explain comorbid phenotypes such as epilepsy, PD, ALS and AD among others (Boison and Aronica, 2015).

Inhibition of ADK strengthens A1AR activation and has a protective effect in ischemia, epilepsy and glutamate excitotoxicity (Boison, 2013). Williams-Karnesky et al. (2013) have demonstrated that epileptogenesis is modulated by intracellular adenosine through the transmethylation pathway. Indeed, seizures in murine models involve alteration of adenosine homeostasis (increased ADK and reduced adenosine), increased DNA methyltransferase activity and increased hippocampal DNA methylation (Williams-Karnesky et al., 2013). Seizure susceptibility was reduced by DNA methyltransferase inhibitors (Williams-Karnesky et al., 2013). Different methods are being tried to increase adenosine in order to reduce seizures. When adenosine-releasing polymers were implanted intraventricularly, methylation reverted to control levels and seizure activity decreased (Williams-Karnesky et al., 2013). Recently, attenuation of epilepsy development in mice has also been obtained after transient application of an ADK inhibitor (Sandau et al., 2019). ADK-deficient stem cells could be a tool to increase adenosine. Poppe et al. (2018) have obtained ADKdeficient epithelial stem cells able to differentiate in neurons and astrocytes with high ability to release adenosine. ADK levels are reduced by ketogenic diet used for the treatment of epilepsy. It is interesting to note that the ketogenic diet suppresses seizures by A1R-dependent and likely also by adenosine-dependent epigenetic mechanisms (Masino et al., 2011; Lusardi et al., 2015; Boison and Rho, 2020).
Transgenic mice with brain-wide or telencephalon ADK hyperexpression showed dysregulation of brain adenosine which resulted in impairment of working memory and of associative memory measured using the conditioned freezing paradigm (Yee et al., 2007; Singer et al., 2012; Singer et al., 2013), while mice with brain-wide deletion of ADK developed spontaneous seizures and profound deficits in hippocampusdependent learning and memory (Sandau et al., 2016).

Recently, Osborne et al. (2018) have distinguished the neurobehavioral consequences of gestational ADK deletion vs. adult-onset ADK deficiency. Interestingly, gestational depletion of $\mathrm{ADK}$ produced deficits in social memory in males, and contextual learning impairments in both sexes, and a hyperresponsiveness to amphetamine in males. In contrast, the tardive astrocyte deficiency of ADK resulted in normal social memory and contextual learning. These results point to a role for adenosine homeostasis during development in the determination of the susceptibility to later neuropsychiatric diseases such as schizophrenia, autism and attention deficit hyperactivity disorder, in which males more frequently express social deficits than females.

Clinical radiation therapy for the treatment of central nervous system tumors leads to impairments in cognition. Adult rats exposed to cranial irradiation showed significant declines in performance of hippocampal-dependent memory tasks such as novel place recognition, novel object recognition and contextual fear conditioning associated to astrogliosis and elevated ADK expression in the hippocampus. The treatment with an ADK inhibitor prior to cranial irradiation improved performance in all cognitive tasks one month post exposure (Acharya et al., 2016).

\section{ADENOSINE DEAMINASE}

ADA catalyzes the deamination of adenosine and deoxyadenosine into inosine a deoxyinosine respectively. There are two genes codifying for ADA: $A D A 1$ and $A D A 2 /$ cat eye syndrome chromosome region, candidate 1 (CECR1) which are localized in the chromosomes 20 and 22, respectively. The proteins have $27 \%$ identity and differ in structure and probably in functions (for recent reviews see Meyts and Aksentijevich, 2018; Moens et al., 2019).

\section{Adenosine deaminase 1}

ADA1 is a $41-\mathrm{kDa}$ monomer protein that is present in all human tissues, with the highest expression in $\mathrm{T}$ and $\mathrm{B}$ lymphocytes. ADA1 plays a crucial role in adaptive immune system development and exhibits an affinity for its substrates adenosine and deoxyadenosine significantly higher than ADA2. ADA1 not only reduces extracellular adenosine concentration preventing adenosine receptor desensitization, but is also able to directly interact with dipeptidyl peptidase-4 (CD26) (Franco et al., 1997) and, by interacting with A1R and $\mathrm{A} 2 \mathrm{R}$, increases receptor functionality in the striatum (Gracia et al., 2008; Ciruela et al., 2010; Gracia et al., 2011). CD26 is more expressed in microglia and astrocytes than in neurons and is more abundant in astrocytes during inflammation and in 
microglia in neuropathy. Spinal application of CD26 inhibitors induces a strong antihyperalgesic effect during inflammatory pain (Kiraly et al., 2018), but the role of ADA1 in CD26 function in the nervous system is unknown.

Moreno et al. (2018) have demonstrated the formation of trimeric complexes CD26-ADA-A2AR and have suggested that ADA could have a role in communication between cells expressing CD26 (such as $\mathrm{T}$ cells) and those expressing adenosine receptors (such as neurons and dendritic cells). If this is the case, ADA deficiency could also affect the cell-cell communication in the nervous system.

Mutations in the ADA1 gene are among the most common causes for severe combined immunodeficiency (SCID). When ADA activity is absent, deoxyadenosine increases both extracellularly and intracellularly. Within cells, it is converted by the action of deoxycytidine kinase and/or adenosine kinase to deoxyadenosine monophosphate and then to deoxyadenosine triphosphate (dATP). Deoxyadenosine and dATP in lymphocytes are considered the main agents of toxicity. The raise of intracellular dATP interferes with DNA synthesis and repair by inhibiting ribonucleotide reductase and terminal deoxynucleotidyl transferase and results in apoptosis of developing thymocytes (for recent reviews Whitmore and Gaspar, 2016; Flinn and Gennery, 2018; Garcia-Gil et al., 2018; Camici et al., 2019) while deoxyadenosine inactivates $\mathrm{SAHH}$, leading to accumulation of SAH and inhibits the transmethylation reactions (Figure 3) which are required for lymphocyte activation.

In addition to immunodeficiency, ADA-SCID patients display skeletal, hepatic, renal and lung alterations, as well as neurological and behavioral impairments such as reduced verbal expression, seizures, learning disability, hyperactivity, attention and hearing deficits (Rogers et al., 2001; Nofech-Mozes et al., 2007; Titman et al., 2008; Garcia-Gil et al., 2018). The accumulation of adenosine and deoxyadenosine caused by $\mathrm{ADA}$ deficiency might contribute to the alterations in the nervous system. Notably, a polymorphism in the ADA1 gene in autistic children with mild intellectual disability has been found to be associated with reduced ADA activity in serum (Stubbs et al., 1982; Bottini et al., 2001; Saccucci et al., 2006). Neurological deficits persist after bone marrow transplant or replacement therapy which do improve the immunological and metabolic aspects of the disease (Honig et al., 2007; Booth and Gaspar, 2009; Cicalese et al., 2016). Recently, the degree of neurological impairment of Ada-/- mouse treated with PEG-ADA has been compared with untreated controls (Sauer et al., 2017). The knockout mice show undetectable ADA activity, increased adenosine in total brain extracts, slightly reduced brain size, alterations in explorative behavior, increased anxiety, reduced pain sensitivity and normal sensorimotor development. Both untreated and PEG-ADA-treated knockout mice exhibited reduced $\mathrm{A} 2 \mathrm{AR}$ level compared to control brains, suggesting that adenosine signaling is affected by ADA deficiency. Adenosine metabolite levels in the brain, ventriculomegaly and pain sensitivity showed a tendency to decrease after PEG-ADA treatment (Sauer et al., 2017) while exploration and anxiety abnormalities remained uncorrected. Therefore, reduction of
A2AR appears to contribute to the phenotype of the Ada-/mice but the involvement of other mechanisms, such as epigenetic alterations have not been addressed. Interestingly, it has been recently reported that when the enzyme replacement therapy with PEG-ADA is performed early, it is effective in improving hearing defects in Ada-/- mice (Xu et al., 2019). ADA enzyme therapy in these mice normalized cochlear adenosine levels, and prevented demyelination while treatment with an A2BR-antagonist improved hearing loss and myelin compaction (Manalo et al., 2020).

\section{Adenosine deaminase 2}

ADA2 has a 100 -fold higher $K_{M}$ for adenosine $(2 \mathrm{mM})$ than ADA1 (Schrader et al., 1978). Therefore, the deaminase activity of ADA2 is low under physiological conditions but could be relevant during inflammation and tumorigenesis, when adenosine levels increase. For recent reviews see Meyts and Aksentijevich (2018) and Moens et al. (2019).

Deficiency of ADA2 arises from mutations affecting catalytic activity, protein dimerization, and secretion of ADA2 and causes vasculopathy and inflammation in many organs and/or hemorrhagic stroke (Navon Elkan et al., 2014; Zhou et al., 2014; Meyts and Aksentijevich, 2018; Gibson et al., 2019; Sahin et al., 2020; Zervou et al., 2020; Sozeri et al., 2021). Less frequent neurological manifestations include spastic diplegia or paraplegia, peripheral polyneuropathy, ataxia, neurosensory deafness, and cerebral atrophy (Meyts and Aksentijevich, 2018). ADA1 activity is not impaired and deoxyadenosine nucleotides do not accumulate in ADA2 deficiency (Meyts and Aksentijevich, 2018).

In addition to its deaminase activity, ADA2 may have a growth factor activity and contrarily to ADA1, does not bind to CD26. $\mathrm{ADA} 2$ is a potent regulator of tumor associated microglia/ macrophages polarization. It has been found highly expressed by tumor associated microglia/macrophages (M2-type) in highgrade glioma. In these cells, paracrine effects induced by ADA2 include activation of MAPK signaling and stimulation of proliferation and migration of glioma cells (Zhu et al., 2017a). Moreover, ADA2/CECR1 mediates cross-talk between macrophages and pericytes in glioblastoma multiforme resulting in pericyte recruitment and migration, and thus promoting tumor angiogenesis (Zhu et al., 2017b).

\section{AMP DEAMINASE}

AMPD converts AMP into IMP by deamination (Figures 1, 2). Together with CD39 and NT5C, it regulates the purine pool of nucleotides. The three genes coding for AMPD, AMPD1, AMPD2, and AMPD3, are differently expressed in various organs and in various types of cells. AMPD1 is highly expressed in skeletal muscle and diaphragm, AMPD2 is mainly expressed in brain, liver, and thymus and AMPD3 is most strongly expressed in erythrocytes (Morisaki et al., 1990; Mahnke-Zizelman and Sabina, 1992). Mutations in AMPD2 result in pontocerebellar hypoplasia due to loss of brainstem and cerebellar parenchyma (Akizu et al., 2013; Marsh et al., 2015; 
Accogli et al., 2017; Kortum et al., 2018; Abreu et al., 2020) but a homozygous AMPD2 frameshift variant has been associated with HSP type 63 (Novarino et al., 2014). AMPD2 plays a role in guanine nucleotide homeostasis by regulating the feedback inhibition of adenosine derivatives on de novo purine synthesis; AMPD2 deficiency results in increase of ATP and decrease of GTP levels, which leads to impairment of GTPdependent initiation of protein synthesis (Akizu et al., 2013). Recently, AMPD1 polymorphisms have been associated to autism risk in Chinese population (Zhang et al., 2015). Studies performed in lymphoblast cell lines obtained from patients have revealed decreased mitochondrial complex I activity compared to control cells. This result is interesting since reduction of transcription of mitochondrial electron transport complex genes has been found in several regions of autism brains (Anitha et al., 2013). Since AMPD1 is particularly enriched in muscle, it would be interesting to study the effects of these variants on the muscle functionality of the autistic patients.

\section{AMP-ACTIVATED PROTEIN KINASE}

AMPK is the principal regulator of cellular energy homeostasis since it is a sensor of the AMP:ATP ratio and mediates the adaptive changes of the cell as a function of the energy charge. In fact, through complex and various signaling pathways, AMPK switches off the anabolic pathways that require ATP and switches on the catabolic pathways that produce ATP (Hardie and Hawley, 2001; Gowans et al., 2013). Increasing evidence supports a relevant role of AMPK in the physiopathology of the central nervous system (Camici et al., 2020). The roles of AMPK in brain and its cross-talk with many hormones in the hypothalamus to mediate their anorexigenic and orexigenic effects as well as thermogenic influences have been thoroughly reviewed (Huynh et al., 2016; Rosso et al., 2016; Peixoto et al., 2017; Liu et al., 2020).

Constant AMPK activation might lead to abnormal functioning and development of the nervous system. We have reported that AMPK activation promotes apoptosis in hippocampal and neuroblastoma cells (Pesi et al., 2000; Garcia-Gil et al., 2003) while other authors have described reduction of axonal growth (Williams et al., 2011) and reduction of synapses (Domise et al., 2019). In addition, it has been reported that dysregulation of the AMPK signaling in motor neurons is an early and common event in ALS (Perera and Turner, 2016) and that psychiatric disorders are also associated with dysregulation of AMPK signaling (Perera and Turner, 2016; Rosso et al., 2016). In particular, it has recently been found that AMPKa1 levels are significantly increased, while AMPKa2 levels are markedly reduced in the hippocampus of AD patients, compared to controls (Zimmermann et al., 2020). These changes in AMPKa expression appeared to be AD specific, since AMPKa1/2 levels were unaffected in either Lewy body dementia or frontotemporal dementia (Zimmermann et al., 2020).

Many research groups have studied the effect of AMPK activation on the development of $\mathrm{AD}$, but the results are controversial. When the effect of metformin, a known activator of AMPK and a drug used for the treatment of type 2 diabetes, has been investigated on cognition deficits, some studies have shown an aggravating effect (Imfeld et al., 2012; Wennberg et al., 2018), whereas others reported a preventive one (Ng et al., 2014; Shi et al., 2019). Metformin has been shown to have a positive effect on AD mouse model (Wang et al., 2020). Recently it has been investigated the possible role of the AMPK isozymes in these conflicting results using mouse models of $\mathrm{AD}$ (Zimmermann et al., 2020). AMPK $\alpha 2$ but not $A M P K \alpha 1$ knockout mice displayed impaired cognition and hippocampal late longterm potentiation (Yang et al., 2020). In contrast, the brainspecific repression of AMPKal attenuated learning and memory deficits and the synaptic failure in mouse models of $\mathrm{AD}$ (Zimmermann et al., 2020). Moreover, AD-associated abnormal eEF2 phosphorylation and de novo protein synthesis reduction were also alleviated by deletion of the AMPKal isoform. This effect is relevant for cognition, since long-term memory requires new protein synthesis (Alberini, 2008). The effects of AMPK on amyloid $\beta$ peptide accumulation, tau aggregation, and oxidative stress have been recently reviewed (Assefa et al., 2020). The role of AMPK in HD and ALS is discussed later in the appropriate sections.

\section{NUCLEOSIDE TRANSPORTERS IN THE BRAIN}

As described in the previous sections, adenosine is produced both extra- and intracellularly and is transported across the cell membrane. Therefore, nucleoside transporters have a major impact on the adenosine level, both inside and outside the cell. The SLC28 gene family encodes the concentrative $\mathrm{Na}^{+}$dependent nucleoside transporters (CNT1-3), while the SLC29 gene family encodes the $\mathrm{Na}^{+}$-independent equilibrative nucleoside transporters (ENT1-4) (Cabrita et al., 2002; Engel et al., 2004; Zhou et al., 2010). Among the concentrative transporters, CNT1, which prefers transport of purine nucleosides, and CNT2, which shows a broader substrate specificity, accepting both purine and pyrimidine nucleosides, are expressed in the brain (Anderson et al., 1996). Although all ENTs have been found in the brain (Anderson et al., 1999a; Anderson et al., 1999b; Engel et al., 2004; Baldwin et al., 2005) only ENT1 and ENT2 appear to be relevant in the purinergic signaling.

\section{Concentrative Transporters}

CNTs are high-affinity inward transporters for adenosine. CNT1 is the first nucleoside transporter defined as a transceptor (PérezTorras et al., 2013), a word deriving from the contraction of transporter and receptor for the coexistence of these two functions (Pastor-Anglada and Pérez-Torras, 2018). The expression of the highly regulated transporter CNT1 (Valdes et al., 2002; Klein et al., 2009), is reduced in several human tumors (Farre et al., 2004; Bhutia et al., 2011). Pérez-Torras et al. (2013) found that the restoration of human CNT1 in pancreatic cancer cells caused an alteration in cell cycle progression and in the 
phosphorylation status of kinases involved in key signaling pathways, promoted polyADPR polymerase activity and nonapoptotic cell death, and decreased cell migration, thus reducing tumor growth. All these effects were mimicked by a translocationdefective human CNT1 variant, indicating that transport is not required for signaling. Although the regulation of CNT1 appears extremely interesting and relevant in tumor biology, its involvement in the effect of adenosine in brain still remains unclear.

CNT2 has been reported to be under the A1R control in hepatocytes (Duflot et al., 2004). A similar cross-talk between CNT2 and A1R appears to operate also in neurons since in situ hybridization in rat brain demonstrated that the prominent expression areas of CNT2 are rich in A1R (Guillén-Gomez et al., 2004; Pastor-Anglada and Pérez-Torras, 2018). Nerve growth factor-induced differentiation in phaeochromocytoma PC12 cells increased progressively CNT2 expression and raised A1R mRNA by 15-fold (Medina-Pulido et al., 2013). Although triggering antagonistic signals in target cells, A1R and A2AR significantly up-regulated CNT2 transport activity, both promoting removal of extracellular adenosine in differentiated neuronal PC12 cells (Medina-Pulido et al., 2013). In an intestinal rat epithelial cell line, through a CNT2 and ADK-mediated mechanism, the addition of adenosine rapidly increased AMP intracellular concentration with a consequent activation of AMPK (Aymerich et al., 2006). The same adenosinedependent AMPK activation has been reported in differentiated neuronal PC12 cells. Interestingly, hypoxia induced a down-regulation of CNT2 and a consequent inactivation of AMPK (Medina-Pulido et al., 2013). Therefore, a functional link between CNT2-mediated adenosine uptake and energy metabolism appears to be present not only in intestinal cells (Aymerich et al., 2006; Huber-Ruano et al., 2010), but also in neuronal cells (Medina-Pulido et al., 2013; Pastor-Anglada and Pérez-Torras, 2018). Brain extracellular adenosine in cats increases during wakefulness and decreases during the spontaneous recovery sleep. The duration and depth of sleep after wakefulness appear to be modulated by adenosine (PorkkaHeiskanen et al., 1997). Guillén-Gomez et al. (2004) demonstrated that total sleep deprivation, which is accompanied by an increase of extracellular adenosine, decreased the amount of CNT2 mRNA in the rat cerebral cortex. Therefore, CNT2 expression appears to be regulated by sleep at transcriptional level. Since CNT2 is far more efficient in the uptake of adenosine than any equilibrative transporter (Parkinson et al., 2011), its specific decrease suggests that this transporter may exert a new physiological role for this transporter in the modulation of extracellular adenosine levels and the sleep/ wakefulness cycle.

\section{Equilibrative Transporters}

ENTs, contrary to CNTs, are widely distributed in all tissues, including the central nervous system, and are considered important components of the purinergic signaling in brain (Pastor-Anglada and Pérez-Torras, 2018). Most studies focus on ENT1 and ENT2; indeed, ENT3 is distributed in intracellular membranes (Baldwin et al., 2005), while ENT4 cannot be considered a conventional nucleoside transporter, but rather a polyspecific cation transporter (Engel et al., 2004). Alterations in the function of ENTs bring about modified levels of adenosine, thus resulting in aberrant purinergic signaling. Mice lacking ENT1 exhibit dysfunctional behaviors, such as decreased ethanol intoxication and excessive ethanol drinking (Choi et al., 2004; Chen et al., 2010), and reduced anxiety-like behavior (Chen et al., 2007; Ruby et al., 2011; Nam et al., 2013). In the dorsomedial striatum of ENT1 null mice, a correlation between higher ethanol consumption and a decreased adenosine-mediated A2AR signaling has been demonstrated (Nam et al., 2013). On the other hand, the lack of ENT1 or the inhibition of ENT1 in the amygdala, leads to an increased adenosine-mediated A1R signaling, which correlates with a reduced anxiety behavior (Choi et al., 2004; Chen et al., 2007). Indeed, since ENT1 mediates nucleoside transport bidirectionally depending on the concentration gradient across the membrane, Ruby et al. (2011) hypothesize that ENT1 mediates a release of adenosine in the striatum (Ruby et al., 2011; Nam et al., 2013), while in the amygdala, ENT1 primarily mediates uptake of adenosine (Choi et al., 2004; Chen et al., 2010; Ruby et al., 2011). In this regard, an important bias of all these studies is the lack of a reliable technique allowing for the detection of adenosine. In fact, the changes in adenosine concentrations have been inferred, but never directly measured.

A correlation between ENT1 expression and epilepsy severity has been reported in rats (Xu et al., 2015; Zhou et al., 2020). In several epilepsy models, adenosine has been shown to exert an anticonvulsant effect (Boison, 2012; Masino et al., 2014), which appears to be mainly mediated by A1R (Li et al., 2007). ENT1 may be considered a therapeutic target for the control of epileptic seizures (Huang et al., 2017). Indeed, intraperitoneal and hippocampal injections of nitrobenzythioinosine (NBTI), a specific inhibitor of ENT1, decreased the number of seizures in rats (Xu et al., 2015), while blood brain barrier permeable ENT1 inhibitors have shown anti-epileptic effects in different mouse models (Ho et al., 2020). Recently, Zhou et al. (2020) demonstrated that, besides NBTI, also the specific inhibition of the 38 MAPK signaling pathway in the brain tissues of rats with acute status epilepticus, reduced the expression levels of ENT1 as well as A1R, the expression of which was significantly increased after seizure induction, probably as adaptive response to an acute attack. The p38 MAPK signaling inhibition decreased pathological damage of hippocampal neurons and reduced frequency of seizures. However, further investigation is needed to clarify the molecular mechanisms underlying the observed effects (Zhou et al., 2020). The expression of ENT1 in HD models and patients is discussed below.

Increasing adenosine by using an ENT1 inhibitor, improved memory deficts in a mouse model of AD (Lee et al., 2018). Studies in non-mammal models have also suggested a role for adenosine signaling and metabolism in learning. For example, antagonists of adenosine receptors, and inhibitors of ENT and ADA were able to prevent the scopolamine-induced amnesia in zebrafish (Bortolotto et al., 2015).

Adenosine has been reported to aberrantly increase in glioblastoma tumors, and the adenosine signaling has been 
associated with increased chemoresistance, migration and invasion, especially in a cell population with an extremely aggressive behavior, called glioblastoma stem-like cells (GSCs) (Niechi et al., 2019; Torres et al., 2019). Recently, Alarcon et al. (2020), using a HPLC technique with fluorescent detection (Torres et al., 2016), demonstrated that extracellular adenosine was significantly increased in GSCs as compared to non-GSCs and that this difference was specifically ascribable to the mesenchymal GSC subtype. A significant reduction in the uptake of adenosine was observed in GSCs as compared to non-GSCs, although mRNA and protein levels of ENT1 were not significantly different (Alarcon et al., 2020). Therefore, posttranslational modifications of the transporter may be relevant in the alteration of its transport efficiency. In this regard, ENT1 has been shown to be regulated by kinase-dependent pathways (Bone et al., 2007; Reyes et al., 2011), and, as discussed below, also protein-protein interaction might contribute to the activity of ENT1.

Although mRNA for ENT2 has been reported to be expressed in brain (Anderson et al., 1999a), ENT2 was suggested to play a major role in the regulation of adenosine levels in the gastrointestinal tract (Morote-Garcia et al., 2009; PastorAnglada and Pérez-Torras, 2018). Its function for the uptake of purine analogs for chemotherapic treatment of various cancer types and its involvement in the cell cycle progression have been recently reviewed by Naes et al. (2020).

\section{Nucleoside Transporter Interactome}

Nucleoside transporters have been considered as independent entities that regulate the traffic of nucleosides across the membrane. However, growing lines of evidence indicate that they may interact with other proteins, therefore belonging to a more complex network (Dos Santos-Rodrigues et al., 2014). For example, glucose-regulated protein 58 (GRP58) and aldolase B were identified as possible partners of CNT2 (Huber-Ruano et al., 2010), therefore a regulatory model dependent on nutrient availability can be postulated for CNT2. Although not yet described, the transceptor role of CNT1 might imply the occurrence of interactions with other proteins, which might explain its function apart from that of nucleoside transporter. Concerning ENT1, the only interactor confirmed so far is calmodulin (Bicket et al., 2016), which could explain, at least in part, the calcium-dependent release of nucleosides in neural cells (Zamzow et al., 2009).

\section{HUNTINGTON'S DISEASE}

$\mathrm{HD}$ is a neurodegenerative disorder that is caused by expanded CAG repeats within the exon- 1 of the gene coding for huntingtin (HTT). CAG repeat lengths of up to 34 are considered to be physiological, while longer CAG repeats are associated to the development of HD. The age of disease onset correlates inversely with CAG repeat length. HD is characterized by involuntary, abnormal movements and postures, psychiatric disturbances, and cognitive alterations (Bates et al., 2015). Research has been performed in cellular and animal models expressing different lengths of CAG repeats (Table 1). For example, the R6/2 mouse expresses exon 1 of the human HTT; the zQ175 mouse expresses a HTT carrying 188 CAG repeats, the Tg51 rat expresses a fragment of the HTT gene with 51 CAG repeats, while Hdh $150 \mathrm{Q}$ is a knock-in mouse expressing the mouse htt gene with $150 \mathrm{CAG}$ repeats (Chou et al., 2005; Li et al., 2015; Lee and Chern, 2014; Guitart et al., 2016; Kao et al., 2017). Downregulation of A2AR has been reported in HD rodent models and also in early stages of the disease in humans (Lee and Chern, 2014). Recent studies suggest that reduced extracellular nucleotide breakdown and reduced glycolysis might contribute to the pathology of $\mathrm{HD}$ (Toczek et al., 2018; HD iPSC Consortium, 2020) and that ENT1 could be a therapeutical target for this disease (Kao et al., 2017). Measures of intracellular concentration of ATP and $\mathrm{NAD}^{+}$, and of the activities of enzymes involved in nucleotide catabolism were performed in the human embryonic kidney cell line HEK 293T transfected with plasmids expressing wild-type or mutant HTT gene. Reduction of intracellular ATP, together with increased ADA activity and reduced activities of ectonucleoside triphosphate diphosphohydrolase, ecto- $5^{\prime}$-nucleotidase and ectosolic ADA, with no changes of AMPD and PNP activities were observed (Toczek et al., 2018). The authors suggested that mutated HTT could interact with and suppress the activity of the extracellular enzymes involved in nucleotide catabolism thereby contributing to HD pathology (Toczek et al., 2018). More recently, human astrocytes and striatal neurons have been obtained from pluripotent stem cells (iPSCs) derived from unaffected individuals and HD patients with HTT gene containing increased number of CAG repeats and used to study the effect of mutant HTT on bioenergetics (HD iPSC Consortium, 2020; Hamilton et al., 2020). While the neurons and astrocytes obtained from iPSCs of control individuals and HD patients had similar levels of ADP and ATP and comparable respiratory and glycolytic activities (Hamilton et al., 2020), the neurons with longer CAG tails, reflecting a more advanced stage of the disease (HD iPSC Consortium, 2020), showed decreased ATP levels and reduced expression of glycolytic enzymes compared to controls. In addition, ATP levels in these HD neurons could be rescued by addition of pyruvate suggesting that the glycolytic deficits play a role in the metabolic disturbance of HD neurons (HD iPSC Consortium, 2020). It would be interesting to test whether the reduced breakdown of ATP takes place in the striatum of HD patients, since this could result in decreased extracellular adenosine and therefore decreased stimulation of the A2AR, which is highly expressed in the striatum and which plays a protective role in this region. Indeed, selective agonists of A2AR reduced DNA damage and oxidative stress-induced apoptosis in HD-iPSC-derived neurons through a cAMP/PKA-dependent pathway (Chiu et al., 2015) and improved motor deficits in mice models of HD (Chou et al., 2005) (Table 1). A role of heteromers of adenosine receptors in HD has been hypothesized but experimental evidence has not yet been provided (Glaser et al., 2020). The decline in energy metabolism observed in HD may be caused both by a gain-of-function of the mutated HTT protein and also by the loss of HTT function. The latter has been demonstrated in cardiomyocytes in which HTT was knocked out 
TABLE 1 | Involvement of adenosine metabolism enzymes, transporters and receptors in HD.

\begin{tabular}{|c|c|c|c|c|c|}
\hline Enzyme/transporter/receptor & Treatment & Model & Expression/activity & Effect & References \\
\hline ADA & & $\begin{array}{l}\text { HEK 293T cells } \\
\text { expressing HTT with } 54 \\
\text { repeats }\end{array}$ & Increased activity & & Toczek et al. (2018) \\
\hline $\begin{array}{l}\text { Ectonucleoside triphosphate } \\
\text { diphosphohydrolase, CD73, } \\
\text { ectosolic ADA }\end{array}$ & & $\begin{array}{l}\text { HEK } 293 T \text { cells } \\
\text { expressing HTT with } 54 \\
\text { repeats }\end{array}$ & Decreased activity & & Toczek et al. (2018) \\
\hline ADA, CD39, CD73 & & $\mathrm{R} 6 / 2$ mouse & No change in expression & & Kao et al. (2017) \\
\hline ADK & & $\mathrm{R} 6 / 2$ mouse & Increased expression & & Kao et al. (2017) \\
\hline ADK & & Hdh150Q mouse & No change in expression & & Kao et al. (2017) \\
\hline AMPK & & $\begin{array}{l}\text { Human,Mouse striatal } \\
\text { neurons }\end{array}$ & Increased expression & & Ju et al. (2011) \\
\hline AMPK & Metformin & $\mathrm{R} 6 / 2$ mouse & & Increased survival & Ma et al. (2007) \\
\hline AMPK & Metformin & Immortalized striatal cells & & Increased survival & Jin et al. (2016) \\
\hline ENT1 & & $\begin{array}{l}\text { zQ175, R6/2 and } \\
\text { Hdh150Q }\end{array}$ & Increased expression & & $\begin{array}{l}\text { Guitart et al. (2016) } \\
\text { Kao et al. (2017) }\end{array}$ \\
\hline ENT1 & $\begin{array}{l}\text { Inhibitor, } \\
\text { knockout }\end{array}$ & $\mathrm{R} 6 / 2$ mouse & & $\begin{array}{l}\text { Increased survival, } \\
\text { increased motor } \\
\text { function }\end{array}$ & Kao et al. (2017) \\
\hline ENT2 & & $\begin{array}{l}\mathrm{R} 6 / 2 \text { and } \mathrm{Hdh} 150 \mathrm{Q} \\
\text { mouse }\end{array}$ & Increased expression & & Kao et al. (2017) \\
\hline A2AR & & $\begin{array}{l}\text { Human, rat and mouse } \\
\text { models }\end{array}$ & Decreased expression & & Lee and Chern (2014) \\
\hline A2AR & & zQ175 mouse & Decreased expression & & Guitart et al. (2016) \\
\hline A2AR & & Tg51 rat & No change in expression & & Guitart et al. (2016) \\
\hline A2AR & Agonist & R $6 / 2$ mouse & & $\begin{array}{l}\text { Decreased motor } \\
\text { deficits }\end{array}$ & Chou et al. (2005) \\
\hline A2AR & Knockout & R $6 / 2$ mouse & & $\begin{array}{l}\text { Increased cognitive } \\
\text { function }\end{array}$ & Li et al. (2015) \\
\hline$A R$ & $\begin{array}{l}\text { Caffeine (non } \\
\text { selective } \\
\text { antagonist) }\end{array}$ & Human & & $\begin{array}{l}\text { Decreased disease } \\
\text { onset }\end{array}$ & Simonin et al. (2013) \\
\hline ARAR gene polymorphisms & & Human & & $\begin{array}{l}\text { Decreased disease } \\
\text { onset }\end{array}$ & $\begin{array}{l}\text { Dhaenens et al. (2009); } \\
\text { Taherzadeh-Fard et al. } \\
\text { (2010) }\end{array}$ \\
\hline$A 1 A R$ & & Human & $\begin{array}{l}\text { Decreased in symptomatic, } \\
\text { increased in } \\
\text { presymptomatic }\end{array}$ & & Matusch et al. (2014) \\
\hline$A 1 A R$ & Agonist & $\begin{array}{l}\text { Rat, 3-nitropropionic } \\
\text { acid infusion }\end{array}$ & & $\begin{array}{l}\text { Attenuation motor } \\
\text { deficit }\end{array}$ & Blum et al. (2002) \\
\hline$A 1 A R$ & Antagonist & $\mathrm{R} 6 / 2$ mouse & $\begin{array}{l}\text { Decreased binding, } \\
\text { increased functionality }\end{array}$ & & Ferrante et al. (2014) \\
\hline
\end{tabular}

by the CRISPR/Cas9 method which showed reduced intracellular ATP and reduced cellular medium concentration of total purine pool (Tomczyk et al., 2020).

Decrease of A2AR has been found in several but not in all HD animal models (Lee and Chern, 2014; Guitart et al., 2016). For example, the number of A2AR antagonist binding sites was not changed in transgenic HD rats with 51 CAG repeats (Tg51 rats). The extracellular level of adenosine measured by in vivo microdialysis was lower in rats with 51 CAG repeats and in mice with 175 CAG repeats compared to their wild type littermates (Guitart et al., 2016). Striatal density of ENT1 expression and the expression of ENT1 transcript were significantly increased in mouse expressing HTT with 175 repeats and in postmortem prefrontal cortex from $\mathrm{HD}$ patients, respectively (Guitart et al., 2016). Moreover, the ratio of adenosine/ATP in the cerebral spinal fluid was negatively correlated with the disease duration. Chronic inhibition of ENT1 or genetic removal of ENT1 enhanced the survival of mice which express exon 1 of the human $H T T$ gene, containing 150 CAG repeats (Kao et al., 2017) (Table 1).

Although the lower adenosine levels found in HD models suggest that increasing adenosine could have a protective role in $\mathrm{HD}$, some reports suggest that the adenosine effect could be symptom-specific. Indeed, activation of A2AR has a beneficial effect on the motor impairment, but inactivation of A2AR in some models improves cognitive function (Blum et al., 2018). $\mathrm{ADK}$ and $\mathrm{ADA}$ contribute to the adenosine tone in the striatum, and some conflicting results obtained in animal models could be due to the specific contribution of these enzymes in compensatory effects among proteins/enzymes that control adenosine homeostasis. For example, ADK transcript and ADK activity are upregulated in the mouse that harbors mutated HTT with 187 repeats but not in the one with150 repeats (Kao et al., 2017).

Metformin intake correlates with improved cognitive functions in $\mathrm{HD}$ patients suffering from diabetes (Hervas 
TABLE 2 | Involvement of adenosine metabolism enzymes and receptors in ALS.

\begin{tabular}{|c|c|c|c|c|c|}
\hline $\begin{array}{l}\text { Enzyme/ } \\
\text { receptor }\end{array}$ & Treatment & Model & Expression/activity & Effect & References \\
\hline ADA & & $\begin{array}{l}\text { Astrocytes from C9orf72 ALS } \\
\text { patients }\end{array}$ & Decreased expression & $\begin{array}{l}\text { Increased cocultured motor neuron } \\
\text { cytotoxicity }\end{array}$ & Allen et al. (2019) \\
\hline AMPK & & $\begin{array}{l}\text { ALS patient-derived } \\
\text { mesenchymal stem cells }\end{array}$ & Decreased expression & & Yun et al. (2019) \\
\hline AMPK & Resveratrol (activator) & $\begin{array}{l}\text { ALS patient-derived } \\
\text { mesenchymal stem cells }\end{array}$ & $\begin{array}{l}\text { Increased expression and } \\
\text { activation }\end{array}$ & Increased differentiation & Yun et al. (2019) \\
\hline AMPK & latrepirdin (activator) & SOD1(G93A) mouse & Increased activity & Delayed disease progression & $\begin{array}{l}\text { Coughlan et al. } \\
(2015)\end{array}$ \\
\hline AMPK & $\begin{array}{l}\text { calorie restricted diet } \\
\text { (activator) }\end{array}$ & SOD1(G93A) mouse & Increased activity & $\begin{array}{l}\text { Decreased neuronal survival and } \\
\text { lifespan }\end{array}$ & Zhao et al. (2015) \\
\hline A2AR & & Human ALS Iymphocyte & Increased expression & & $\begin{array}{l}\text { Vincenzi et al. } \\
(2013)\end{array}$ \\
\hline A2AR & & Human, spinal cord & Increased expression & & $\mathrm{Ng}$ et al. (2015) \\
\hline A2AR & & $\begin{array}{l}\text { SOD1(G93A) mouse, spinal } \\
\text { cord }\end{array}$ & $\begin{array}{l}\text { Increased expression } \\
\text { (disease onset) }\end{array}$ & & $\mathrm{Ng}$ et al. (2015) \\
\hline A2AR & & $\begin{array}{l}\text { SOD1(G93A) mouse, spinal } \\
\text { cord }\end{array}$ & $\begin{array}{l}\text { Decreased expression (later } \\
\text { disease stage) }\end{array}$ & & $\begin{array}{l}\text { Potenza et al. } \\
(2013)\end{array}$ \\
\hline A2AR & Knockout inhibitor & SOD1(G93A) mouse & & $\begin{array}{l}\text { Increased neuronal survival, delayed } \\
\text { disease progression }\end{array}$ & $\mathrm{Ng}$ et al. (2015) \\
\hline A2AR & $\begin{array}{l}\text { caffeine (non selective } \\
\text { antagonist) }\end{array}$ & SOD1(G93A) mouse & & Decreased survival & $\begin{array}{l}\text { Potenza et al. } \\
\text { (2013) }\end{array}$ \\
\hline
\end{tabular}

et al., 2017). It is known that metformin has a protective effect in HD cell models through activation of AMPK and modulation of mitochondrial dynamics (Jin et al., 2016). However, nuclear localization of AMPKa1 has been reported in the brain tissue of HD patients and it has been demonstrated to potentiate striatal neurodegeneration in HD models (Ju et al., 2011) (Table 1). This raises the possibility that there could be a therapeutical window for AMPK activation and that it should be used at early stages since activation during the late stages of HD might be deleterious. However, more research is necessary to understand the role of AMPKal and the possible protective effects of metformin on targets different from AMPK.

\section{AMYOTROPHIC LATERAL SCLEROSIS}

ALS is characterized by degeneration of both upper and lower motor neurons which leads to progressive weakness and ultimately to death. In addition, there might be extra-motor manifestations including alteration of some cognitive functions, and processing of emotions. In about $10 \%$ of cases, frontotemporal dementia has been associated with ALS (Benbrika et al., 2019). Ninety per cent of ALS cases are sporadic and more than 35 genes have been linked to the disease. The main genes involved in the familial forms are those coding for the superoxide dismutase (SOD1), TAR DNA binding protein (TARDBP), chromosome 9 open reading frame 72 (C9orf72) and fused in sarcoma (FUS). Disturbances in RNA metabolism, impaired protein homeostasis, nucleocytoplasmic transport defects, impaired DNA repair, excitotoxicity, mitochondrial dysfunction, oxidative stress, axonal transport disruption, neuroinflammation, oligodendrocyte dysfunction, and vesicular transport defects have been proposed to contribute to ALS pathogenesis (Rothstein, 2009; Mejzini et al., 2019; Floare and Allen, 2020).

It has been hypothesized that, at least in some types of ALS, neurodegeneration could be the result of a higher susceptibility to oxidative stress and experiments designed to test it have pointed to the involvement of AMPK activation. The transgenic mouse SOD1(G93A), that overexpresses a human SOD1 with the substitution of glycine 93 to alanine, is the model of a fifth of the familial cases of ALS (Rosen et al., 1993). Embryonic neural stem cells from these mice exhibited more phosphorylated AMPK and were more susceptible to apoptosis in the presence of oxidative stress compared to those obtained from wild type animals, while treatment with compound $\mathrm{C}$, an inhibitor of AMPKa, attenuated the effects of $\mathrm{H}_{2} \mathrm{O}_{2}$ (Sui et al., 2014). Strong activation of AMPK was also found in lumbar spinal cords of SOD1(G93A) mice (Coughlan et al., 2015). However, when these mice were treated with the AMPK activator latrepirdine from postnatal day 70 to day 120 , they showed a delayed symptom onset and a significant increase in life span compared to untreated mice (Coughlan et al., 2015). These protective effects were not observed when stimulation of AMPK was obtained through a calorie-restricted diet. Indeed, this diet reduced motor neuron survival and reduced lifespan, while lifespan was increased and disease onset was delayed in the SOD1(G93A) mice fed with a high fat diet (Zhao et al., 2015). These experiments are summarized in Table 2. Therefore, these results point to inhibition, and not to activation of AMPK as a therapeutic strategy for ALS.

Although many studies have shown that purinergic signaling is altered in ALS, it is not yet clear whether these changes are compensatory or causative. An up-regulation of A2ARs was observed in lymphocytes of ALS patients with 
respect to healthy subjects (Vincenzi et al., 2013), and, at the symptomatic onset, in the spinal cords of SOD1(G93A) mice and end-stage human ALS spinal cords ( $\mathrm{Ng}$ et al., 2015). In addition, adenosine induced embryonic stem cell-derived motor neuron cell death in cultures while pharmacological inhibition and partial genetic ablation of A2AR protected motor neurons from cell death and delayed disease progression of SOD1(G93A) mice (Ng et al., 2015) (Table 2). Sebastiao et al. (2018) have suggested that A2AR stimulation or inhibition could play a different role at early and late stages of ALS, since accumulating lines of evidence indicate a beneficial role of both agonists and antagonists of A2AR.

Recent studies have shown that mesenchymal stem cells derived from ALS patients have limited stem cell capacities and exhibit cellular senescence phenotype suggesting that they should be improved before being used in autologous stem cell therapy. Yun et al. (2019) have reported down-regulated AMPK/ sirtuin 1 signaling in these cells and have found that resveratrol, which independently stimulates both AMPK and sirtuin 1 (Dasgupta and Milbrandt, 2007; Gertz et al., 2012) restored AMPK/sirtuin 1 and increased differentiation of mesenchymal stem cells into neuron-like cells.

Another recent interesting observation regarding adenosine metabolism has been reported in ALS characterized by a massive hexanucleotide repeat expansion within C9orf72 (DeJesusHernandez et al., 2011; Renton et al., 2011). ADA levels are reduced in fibroblasts, and in both astrocytes and neurons obtained from induced-neuroprogenitor cells from individuals with either C9orf72 mutation or with sporadic ALS (Allen et al., 2019) (Table 2). In vitro experiments have shown that, when ADA reduction was bypassed by inosine supplementation, the bioenergetic flux and ATP levels increased in induced-astrocytes and that the induced astrocyte-mediated motor neuron cell death was reduced (Allen et al., 2019). Allen et al. (2019) have suggested that inosine supplementation, in combination with modulation of the level of ADA may represent a beneficial therapeutic approach in ALS patients.

\section{CONCLUDING REMARKS}

Adenosine and ATP can be released by neurons, astrocytes, oligodendrocytes and microglia and these cells express receptors for both signaling molecules. Adenosine not only acts as neurotransmitter and neuromodulator, but it is also a metabolic sensor in the brain and contributes to the communication between the different cells fine-controlling synaptic circuitry and neuroinflammation. Nucleoside transporters and/or enzymatic activities involved in the metabolism of adenosine, by affecting the levels of both ATP and adenosine, and therefore the activity of adenosine and ATP receptors, impact on many physiological processes. They could have a role in the onset or the development of central nervous system disorders, and be possible targets of drugs for their treatment. The adenosine concentration must be strictly regulated. Indeed, adenosine (and deoxyadenosine) accumulation such as in ADA deficiency, results in severe combined immunodeficiency associated with neurological deficits. Decrease of adenosine is observed in several pathological conditions, as in epilepsy, in which $\mathrm{ADK}$ is increased. ADK not only decreases adenosine levels, but also regulates the transmethylation pathway. Both increase in adenosine and DNA methylation inhibition have a protective role in this pathology. Some studies point to the use of ENT inhibition to increase adenosine levels and ENT inhibitors with the ability to cross the brain blood barrier have been used with antiepileptic activity in animal models. The use of ENT1 inhibitors has also been proposed for HD. In this regard, most studies would find a sound support from the setting-up of reliable techniques for the direct determination of adenosine levels in different physiological and pathological conditions.

Many times, the information available from cell and animal models and patients does not clarify whether the changes in adenosine metabolism or signaling are causative or compensative. However, it has to be considered that often compensatory changes occur during the development of the diseases, and there could be temporal windows when a drug could be effective. In other cases, when the energetic state of the cells is involved, modulation of AMPK has been hypothesized to be a target to improve neurodegeneration and/or cognitive impairment. Although stimulation of AMPK improves impairments in stem cell properties derived from ALS patients, the studies in mouse models indicate that different effects could result from distinct activation pathways of the enzyme, and from the AMPK isozyme localization. Notably, in diabetic patients with $\mathrm{AD}$ or HD comorbidity, metformin appears to prevent cognitive decline. Increased knowledge on adenosine metabolism in diseases could provide new tools of intervention. As an example, in the C9orf72 type of ALS, reduced ADA activity and in vitro models of disease have led to the hypothesis that inosine could have a protective effect. However, it is clear that much research is still necessary to understand the adenosine metabolism and the cross-talk of different cell types in different regions of the brain and also their temporal variations under physiological and pathological conditions in order to design new therapeutical tools.

\section{AUTHOR CONTRIBUTIONS}

MG-G conceived the manuscript; MC, MG-G and MGT wrote the draft manuscript. SA and RP collected references and drew the figures. All authors discussed the content.

\section{FUNDING}

This work was supported by a local grant of the University of Pisa to MG-G [408-60\%(2020)]. 


\section{REFERENCES}

Abreu, N. J., Koboldt, D. C., Gastier-Foster, J. M., Dave-Wala, A., Flanigan, K. M., and Waldrop, M. A. (2020). Homozygous Variants in AMPD2 and COL11A1 Lead to a Complex Phenotype of Pontocerebellar Hypoplasia Type 9 and Stickler Syndrome Type 2. Am. J. Med. Genet. 182 (3), 557-560. doi:10.1002/ ajmg.a.61452

Accogli, A., Iacomino, M., Pinto, F., Orsini, A., Vari, M. S., Selmi, R., et al. (2017). Novel AMPD2 Mutation in Pontocerebellar Hypoplasia, Dysmorphisms, and Teeth Abnormalities. Neurol. Genet. 3 (5), e179. doi:10.1212/NXG. 0000000000000179

Acharya, M. M., Baulch, J. E., Lusardi, T. A., Allen, B. D., Chmielewski, N. N., Baddour, A. A. D., et al. (2016). Adenosine Kinase Inhibition Protects against Cranial Radiation-Induced Cognitive Dysfunction. Front. Mol. Neurosci. 9, 42. doi:10.3389/fnmol.2016.00042

Agostinho, P., Madeira, D., Dias, L., Simões, A. P., Cunha, R. A., and Canas, P. M. (2020). Purinergic Signaling Orchestrating Neuron-Glia Communication. Pharmacol. Res. 162, 105253. doi:10.1016/j.phrs.2020.105253

Akizu, N., Cantagrel, V., Schroth, J., Cai, N., Vaux, K., McCloskey, D., et al. (2013). AMPD2 Regulates GTP Synthesis and Is Mutated in a Potentially Treatable Neurodegenerative Brainstem Disorder. Cell 154 (3), 505-517. doi:10.1016/j. cell.2013.07.005

Alarcón, S., Toro, M. d. 1. Á., Villarreal, C., Melo, R., Fernández, R., Ayuso Sacido, A., et al. (2020). Decreased Equilibrative Nucleoside Transporter 1 (ENT1) Activity Contributes to the High Extracellular Adenosine Levels in Mesenchymal Glioblastoma Stem-like Cells. Cells 9 (8), 1914. doi:10.3390/ cells 9081914

Alberini, C. M. (2008). The Role of Protein Synthesis during the Labile Phases of Memory: Revisiting the Skepticism. Neurobiol. Learn. Mem. 89 (3), 234-246. doi:10.1016/j.nlm.2007.08.007

Alhusani, A., Obaid, A., Blom, H., Wedell, A., and Alfadhel, M. (2019). Adenosine Kinase Deficiency: Report and Review. Neuropediatrics 50 (1), 046-050. doi:10. 1055/s-0038-1676053

Allegrini, S., Scaloni, A., Careddu, M. G., Cuccu, G., D'Ambrosio, C., Pesi, R., et al. (2004). Mechanistic Studies on Bovine Cytosolic 5'-nucleotidase II, an Enzyme Belonging to the HAD Superfamily. Eur. J. Biochem. 271, 4881-4891. doi:10. 1111/j.1432-1033.2004.04457.x

Allen, S. P., Hall, B., Castelli, L. M., Francis, L., Woof, R., Siskos, A. P., et al. (2019). Astrocyte Adenosine Deaminase Loss Increases Motor Neuron Toxicity in Amyotrophic Lateral Sclerosis. Brain 142 (3), 586-605. doi:10.1093/brain/ awy353

Alonso-Andrés, P., Albasanz, J. L., Ferrer, I., and Martín, M. (2018). Purine-related Metabolites and Their Converting Enzymes Are Altered in Frontal, Parietal and Temporal Cortex at Early Stages of Alzheimer's Disease Pathology. Brain Pathol. 28 (6), 933-946. doi:10.1111/bpa.12592

Alves, V. S., Leite-Aguiar, R., Silva, J. P. d., Coutinho-Silva, R., and Savio, L. E. B. (2020). Purinergic Signaling in Infectious Diseases of the Central Nervous System. Brain Behav. Immun. 89, 480-490. doi:10.1016/j.bbi.2020.07.026

Anderson, C. M., Baldwin, S. A., Young, J. D., Cass, C. E., and Parkinson, F. E. (1999a). Distribution of mRNA Encoding a Nitrobenzylthioinosine-Insensitive Nucleoside Transporter (ENT2) in Rat Brain. Mol. Brain Res. 70 (2), 293-297. doi:10.1016/s0169-328x(99)00164-3

Anderson, C. M., Xiong, W., Geiger, J. D., Young, J. D., Cass, C. E., Baldwin, S. A., et al. (1999b). Distribution of Equilibrative, Nitrobenzylthioinosine-Sensitive Nucleoside Transporters (ENT1) in Brain. J. Neurochem. 73 (2), 867-873. doi:10.1046/j.1471-4159.1999.0730867.x

Anderson, C. M., Xiong, W., Young, J. D., Cass, C. E., and Parkinson, F. E. (1996). Demonstration of the Existence of mRNAs Encoding N1/cif and N2/cit Sodium/nucleoside Cotransporters in Rat Brain. Mol. Brain Res. 42 (2), 358-361. doi:10.1016/s0169-328x(96)00244-6

Anitha, A., Nakamura, K., Thanseem, I., Matsuzaki, H., Miyachi, T., Tsujii, M., et al. (2013). Downregulation of the Expression of Mitochondrial Electron Transport Complex Genes in Autism Brains. Brain Pathol. 23 (3), 294-302. doi:10.1111/bpa.12002

Ashby, B., and Holmsen, H. (1983). Platelet AMP Deaminase. Regulation by MgATP2- and Inorganic Phosphate and Inhibition by the Transition State Analog
Coformycin. J. Biol. Chem. 258 (6), 3668-3672. doi:10.1016/s0021-9258(18) 32717-0

Assefa, B. T., Tafere, G. G., Wondafrash, D. Z., and Gidey, M. T. (2020). The Bewildering Effect of AMPK Activators in Alzheimer's Disease: Review of the Current Evidence. Biomed. Res. Int. 2020, 1-18. doi:10.1155/2020/9895121

Augusto, E., Matos, M., Sevigny, J., El-Tayeb, A., Bynoe, M. S., Muller, C. E., et al. (2013). Ecto-5'-nucleotidase (CD73)-Mediated Formation of Adenosine Is Critical for the Striatal Adenosine A2A Receptor Functions. J. Neurosci. 33 (28), 11390-11399. doi:10.1523/JNEUROSCI.5817-12.2013

Aymerich, I., Foufelle, F., Ferré, P., Casado, F. J., and Pastor-Anglada, M. (2006). Extracellular Adenosine Activates AMP-dependent Protein Kinase (AMPK). J. Cell Sci. 119 (Pt 8), 1612-1621. doi:10.1242/jcs.02865

Baldwin, S. A., Beal, P. R., Yao, S. Y., King, A. E., Cass, C. E., and Young, J. D. (2004). The Equilibrative Nucleoside Transporter Family, SLC29. Pflugers Arch. 447 (5), 735-743. doi:10.1007/s00424-003-1103-2

Baldwin, S. A., Yao, S. Y. M., Hyde, R. J., Ng, A. M. L., Foppolo, S., Barnes, K., et al. (2005). Functional Characterization of Novel Human and Mouse Equilibrative Nucleoside Transporters (hENT3 and mENT3) Located in Intracellular Membranes. J. Biol. Chem. 280 (16), 15880-15887. doi:10.1074/jbc. M414337200

Bannon, N. M., Chistiakova, M., Chen, J.-Y., Bazhenov, M., and Volgushev, M. (2017). Adenosine Shifts Plasticity Regimes between Associative and Homeostatic by Modulating Heterosynaptic Changes. J. Neurosci. 37 (6), 1439-1452. doi:10.1523/JNEUROSCI.2984-16.2016

Barros-Barbosa, A. R., Ferreirinha, F., Oliveira, Â., Mendes, M., Lobo, M. G., Santos, A., et al. (2016). Adenosine A2A Receptor and Ecto-5'-nucleotidase/ CD73 Are Upregulated in Hippocampal Astrocytes of Human Patients with Mesial Temporal Lobe Epilepsy (MTLE). Purinergic Signal. 12 (4), 719-734. doi:10.1007/s11302-016-9535-2

Barsotti, C., Pesi, R., Felice, F., and Ipata, P. L. (2003). The Purine Nucleoside Cycle in Cell-free Extracts of Rat Brain: Evidence for the Occurrence of an Inosine and a Guanosine Cycle with Distinct Metabolic Roles. Cell Mol. Life Sci. (Cmls) 60 (4), 786-793. doi:10.1007/s00018-003-2371-x

Bates, G. P., Dorsey, R., Gusella, J. F., Hayden, M. R., Kay, C., Leavitt, B. R., et al. (2015). Huntington Disease. Nat. Rev. Dis. Primers 1, 15005. doi:10.1038/nrdp. 2015.5

Becker, P.-H., Demir, Z., Mozer Glassberg, Y., Sevin, C., Habes, D., Imbard, A., et al. (2021). Adenosine Kinase Deficiency: Three New Cases and Diagnostic Value of Hypermethioninemia. Mol. Genet. Metab. 132 (1), 38-43. doi:10.1016/ j.ymgme.2020.11.007

Benbrika, S., Desgranges, B., Eustache, F., and Viader, F. (2019). Cognitive, Emotional and Psychological Manifestations in Amyotrophic Lateral Sclerosis at Baseline and Overtime: A Review. Front. Neurosci. 13, 951. doi:10.3389/fnins.2019.00951

Bhutia, Y. D., Hung, S. W., Patel, B., Lovin, D., and Govindarajan, R. (2011). CNT1 Expression Influences Proliferation and Chemosensitivity in Drug-Resistant Pancreatic Cancer Cells. Cancer Res. 71 (5), 1825-1835. doi:10.1158/0008-5472. CAN-10-2736

Bicket, A., Mehrabi, P., Naydenova, Z., Wong, V., Donaldson, L., Stagljar, I., et al. (2016). Novel Regulation of Equlibrative Nucleoside Transporter 1 (ENT1) by Receptor-Stimulated Ca2+-dependent Calmodulin Binding. Am. J. Physiology-Cell Physiol. 310 (10), C808-C820. doi:10.1152/ajpcell.00243.2015

Bjelobaba, I., Parabucki, A., Lavrnja, I., Stojkov, D., Dacic, S., Pekovic, S., et al. (2011). Dynamic Changes in the Expression Pattern of Ecto-5' - Nucleotidase in the Rat Model of Cortical Stab Injury. J. Neurosci. Res. 89 (6), 862-873. doi:10. 1002/jnr.22599

Bjursell, M. K., Blom, H. J., Cayuela, J. A., Engvall, M. L., Lesko, N., Balasubramaniam, S., et al. (2011). Adenosine Kinase Deficiency Disrupts the Methionine Cycle and Causes Hypermethioninemia, Encephalopathy, and Abnormal Liver Function. Am. J. Hum. Genet. 89 (4), 507-515. doi:10. 1016/j.ajhg.2011.09.004

Blackstone, C. (2018). Converging Cellular Themes for the Hereditary Spastic Paraplegias. Curr. Opin. Neurobiol. 51, 139-146. doi:10.1016/j.conb.2018. 04.025

Blum, D., Chern, Y., Domenici, M. R., Buée, L., Lin, C.-Y., Rea, W., et al. (2018). The Role of Adenosine Tone and Adenosine Receptors in Huntington's Disease. J. Caffeine Adenosine Res. 8 (2), 43-58. doi:10.1089/caff.2018.0006 
Blum, D., Gall, D., Galas, M.-C., d'Alcantara, P., Bantubungi, K., and Schiffmann, S. N. (2002). The Adenosine A1Receptor Agonist Adenosine Amine Congener Exerts a Neuroprotective Effect against the Development of Striatal Lesions and Motor Impairments in the 3-Nitropropionic Acid Model of Neurotoxicity. J. Neurosci. 22 (20), 9122-9133. doi:10.1523/jneurosci.22-20-09122.2002

Bodin, P., and Burnstock, G. (2001). Purinergic Signalling: ATP Release. Neurochem. Res. 26 (8-9), 959-969. doi:10.1023/a:1012388618693

Boison, D. (2012). Adenosine Dysfunction in Epilepsy. Glia 60 (8), 1234-1243. doi:10.1002/glia.22285

Boison, D. (2013). Adenosine Kinase: Exploitation for Therapeutic Gain. Pharmacol. Rev. 65 (3), 906-943. doi:10.1124/pr.112.006361

Boison, D. (2016). Adenosinergic Signaling in Epilepsy. Neuropharmacology 104, 131-139. doi:10.1016/j.neuropharm.2015.08.046

Boison, D., and Aronica, E. (2015). Comorbidities in Neurology: Is Adenosine the Common Link? Neuropharmacology 97, 18-34. doi:10.1016/j.neuropharm. 2015.04.031

Boison, D., and Jarvis, M. F. (2020). Adenosine Kinase: A Key Regulator of Purinergic Physiology. Biochem. Pharmacol. 114321, 114321. doi:10.1016/j. bcp.2020.114321

Boison, D., and Rho, J. M. (2020). Epigenetics and Epilepsy Prevention: The Therapeutic Potential of Adenosine and Metabolic Therapies. Neuropharmacology 167, 107741. doi:10.1016/j.neuropharm.2019.107741

Bonan, C. D. (2012). Ectonucleotidases and Nucleotide/nucleoside Transporters as Pharmacological Targets for Neurological Disorders. CNS Neurol. Disord. Drug Targets 11 (6), 739-750. doi:10.2174/187152712803581092

Bonan, C. D., Walz, R., Pereira, G. S., Worm, P. V., Battastini, A. M. O., Cavalheiro, E. A., et al. (2000). Changes in Synaptosomal Ectonucleotidase Activities in Two Rat Models of Temporal Lobe Epilepsy. Epilepsy Res. 39 (3), 229-238. doi:10. 1016/s0920-1211(00)00095-4

Bone, D. B. J., Robillard, K. R., Stolk, M., and Hammond, J. R. (2007). Differential Regulation of Mouse Equilibrative Nucleoside Transporter 1 (mENT1) Splice Variants by Protein Kinase CK2. Mol. Membr. Biol. 24 (4), 294-303. doi:10. 1080/09687860701210617

Booth, C., and Gaspar, H. B. (2009). Pegademase Bovine (PEG-ADA) for the Treatment of Infants and Children with Severe Combined Immunodeficiency (SCID). Biologics 3, 349-358. doi:10.2147/BTT.S3103

Borroto-Escuela, D. O., Ferraro, L., Narvaez, M., Tanganelli, S., Beggiato, S., Liu, F., et al. (2020). Multiple Adenosine-Dopamine (A2A-D2 like) Heteroreceptor Complexes in the Brain and Their Role in Schizophrenia. Cells 9 (5), 1077. doi:10.3390/cells9051077

Borroto-Escuela, D. O., Wydra, K., Fores-Pons, R., Vasudevan, L., RomeroFernandez, W., Frankowska, M., et al. (2021). The Balance of MU-Opioid, Dopamine D2 and Adenosine A2A Heteroreceptor Complexes in the Ventral Striatal-Pallidal GABA Antireward Neurons May Have a Significant Role in Morphine and Cocaine Use Disorders. Front. Pharmacol. 12, 627032. doi:10. 3389/fphar.2021.627032

Bortolotto, J. W., de Melo, G. M., Cognato, G. D. P., Vianna, M. R. M., and Bonan, C. D. (2015). Modulation of Adenosine Signaling Prevents ScopolamineInduced Cognitive Impairment in Zebrafish. Neurobiol. Learn. Mem. 118, 113-119. doi:10.1016/j.nlm.2014.11.016

Bottini, N., De Luca, D., Saccucci, P., Fiumara, A., Elia, M., Porfirio, M. C., et al. (2001). Autism: Evidence of Association with Adenosine Deaminase Genetic Polymorphism. Neurogenetics 3 (2), 111-113. doi:10.1007/s100480000104

Braun, N., Zhu, Y., Krieglstein, J., Culmsee, C., and Zimmermann, H. (1998). Upregulation of the Enzyme Chain Hydrolyzing Extracellular ATP after Transient Forebrain Ischemia in the Rat. J. Neurosci. 18 (13), 4891-4900. doi:10.1523/jneurosci.18-13-04891.1998

Burnstock, G. (2017). Purinergic Signaling in the Cardiovascular System. Circ. Res. 120 (1), 207-228. doi:10.1161/CIRCRESAHA.116.309726

Cabrita, M. A., Baldwin, S. A., Young, J. D., and Cass, C. E. (2002). Molecular Biology and Regulation of Nucleoside and Nucleobase Transporter Proteins in Eukaryotes and Prokaryotes. Biochem. Cell Biol. 80 (5), 623-638. doi:10.1139/o02-153

Camici, M., Allegrini, S., and Tozzi, M. G. (2018a). Interplay between Adenylate Metabolizing Enzymes and AMP-activated Protein Kinase. FEBS J. 285, 3337-3352. doi:10.1111/febs.14508

Camici, M., Garcia-Gil, M., Allegrini, S., Pesi, R., and Tozzi, M. G. (2020). Evidence for a Cross-Talk between Cytosolic $5^{\prime}$-Nucleotidases and AMP-Activated Protein Kinase. Front. Pharmacol. 11, 609849. doi:10.3389/fphar.2020.609849
Camici, M., Garcia-Gil, M., Pesi, R., Allegrini, S., and Tozzi, M. G. (2019). PurineMetabolising Enzymes and Apoptosis in Cancer. Cancers 11 (9), 1354. doi:10. 3390/cancers11091354

Camici, M., Garcia-Gil, M., and Tozzi, M. (2018b). The Inside Story of Adenosine. Int. J. Mol. Sci. 19 (3), 784. doi:10.3390/ijms19030784

Careddu, M. G., Allegrini, S., Pesi, R., Camici, M., Garcia-Gil, M., and Tozzi, M. G. (2008). Knockdown of Cytosolic 5'-nucleotidase II (cN-II) Reveals that its Activity Is Essential for Survival in Astrocytoma Cells. Biochim. Biophys. Acta (Bba) - Mol. Cell Res. 1783 (8), 1529-1535. doi:10.1016/j.bbamcr.2008.03.018 Carmo, M., Gonçalves, F. Q., Canas, P. M., Oses, J. P., Fernandes, F. D., Duarte, F. V., et al. (2019). Enhanced ATP Release and CD73-mediated Adenosine Formation Sustain Adenosine A 2A Receptor Over-activation in a Rat Model of Parkinson's Disease. Br. J. Pharmacol. 176 (18), 3666-3680. doi:10.1111/bph.14771

Cellai, L., Carvalho, K., Faivre, E., Deleau, A., Vieau, D., Buée, L., et al. (2018). The Adenosinergic Signaling: A Complex but Promising Therapeutic Target for Alzheimer's Disease. Front. Neurosci. 12, 520. doi:10.3389/fnins.2018.00520

Chen, J.-F. (2014). Adenosine Receptor Control of Cognition in Normal and Disease. Int. Rev. Neurobiol. 119, 257-307. doi:10.1016/B978-0-12-801022-8. 00012-X

Chen, J., Nam, H. W., Lee, M. R., Hinton, D. J., Choi, S., Kim, T., et al. (2010). Altered Glutamatergic Neurotransmission in the Striatum Regulates Ethanol Sensitivity and Intake in Mice Lacking ENT1. Behav. Brain Res. 208 (2), 636-642. doi:10.1016/j.bbr.2010.01.011

Chen, J., Rinaldo, L., Lim, S.-J., Young, H., Messing, R. O., and Choi, D.-S. (2007). The Type 1 Equilibrative Nucleoside Transporter Regulates Anxiety-like Behavior in Mice. Genes Brain Behav. 6 (8), 776-783. doi:10.1111/j.1601183X.2007.00311.x

Chiu, F.-L., Lin, J.-T., Chuang, C.-Y., Chien, T., Chen, C.-M., Chen, K.-H., et al. (2015). Elucidating the Role of the A2Aadenosine Receptor in Neurodegeneration Using Neurons Derived from Huntington's Disease iPSCs. Hum. Mol. Genet. 24 (21), 6066-6079. doi:10.1093/hmg/ddv318

Choi, D.-S., Cascini, M.-G., Mailliard, W., Young, H., Paredes, P., McMahon, T., et al. (2004). The Type 1 Equilibrative Nucleoside Transporter Regulates Ethanol Intoxication and Preference. Nat. Neurosci. 7 (8), 855-861. doi:10. 1038/nn1288

Chou, S.-Y., Lee, Y.-C., Chen, H.-M., Chiang, M.-C., Lai, H.-L., Chang, H.-H., et al. (2005). CGS21680 Attenuates Symptoms of Huntington's Disease in a Transgenic Mouse Model. J. Neurochem. 93 (2), 310-320. doi:10.1111/j. 1471-4159.2005.03029.x

Cicalese, M. P., Ferrua, F., Castagnaro, L., Pajno, R., Barzaghi, F., Giannelli, S., et al. (2016). Update on the Safety and Efficacy of Retroviral Gene Therapy for Immunodeficiency Due to Adenosine Deaminase Deficiency. Blood 128 (1), 45-54. doi:10.1182/blood-2016-01-688226

Ciruela, F., Albergaria, C., Soriano, A., Cuffí, L., Carbonell, L., Sánchez, S., et al. (2010). Adenosine Receptors Interacting Proteins (ARIPs): Behind the Biology of Adenosine Signaling. Biochim. Biophys. Acta (Bba) - Biomembranes 1798 (1), 9-20. doi:10.1016/j.bbamem.2009.10.016

Costenla, A. R., Diógenes, M. J., Canas, P. M., Rodrigues, R. J., Nogueira, C., Maroco, J., et al. (2011). Enhanced Role of Adenosine A2A Receptors in the Modulation of LTP in the Rat hippocampus upon Ageing. Eur. J. Neurosci. 34 (1), 12-21. doi:10.1111/j.1460-9568.2011.07719.x

Coughlan, K. S., Mitchem, M. R., Hogg, M. C., and Prehn, J. H. M. (2015) "Preconditioning" with Latrepirdine, an Adenosine 5'-MonophosphateActivated Protein Kinase Activator, Delays Amyotrophic Lateral Sclerosis Progression in SOD1G93A Mice. Neurobiol. Aging 36 (2), 1140-1150. doi:10.1016/j.neurobiolaging.2014.09.022

Cross-Disorder Group of the Psychiatric Genomics Consortium (2013). Identification of Risk Loci with Shared Effects on Five Major Psychiatric Disorders: a Genome-wide Analysis. Lancet 381, 1371-1379. doi:10.1016/ S0140-6736(12)62129-1

Cui, X. A., Singh, B., Park, J., and Gupta, R. S. (2009). Subcellular Localization of Adenosine Kinase in Mammalian Cells: The Long Isoform of AdK Is Localized in the Nucleus. Biochem. Biophysical Res. Commun. 388 (1), 46-50. doi:10. 1016/j.bbrc.2009.07.106

Cunha, R. A., and Agostinho, P. M. (2010). Chronic Caffeine Consumption Prevents Memory Disturbance in Different Animal Models of Memory Decline. Jad 20 (Suppl. 1), S95-S116. doi:10.3233/JAD-2010-1408 
Cunha, R. A. (2016). How Does Adenosine Control Neuronal Dysfunction and Neurodegeneration? J. Neurochem. 139 (6), 1019-1055. doi:10.1111/jnc.13724

Darvish, H., Azcona, L. J., Tafakhori, A., Ahmadi, M., Ahmadifard, A., and PaisánRuiz, C. (2017). Whole Genome Sequencing Identifies a Novel Homozygous Exon Deletion in the NT5C2 Gene in a Family with Intellectual Disability and Spastic Paraplegia. Npj Genomic Med. 2, 20. doi:10.1038/s41525-017-0022-7

Dasgupta, B., and Milbrandt, J. (2007). Resveratrol Stimulates AMP Kinase Activity in Neurons. Proc. Natl. Acad. Sci. 104 (17), 7217-7222. doi:10.1073/pnas. 0610068104

de Groot, M., Iyer, A., Zurolo, E., Anink, J., Heimans, J. J., Boison, D., et al. (2012). Overexpression of ADK in Human Astrocytic Tumors and Peritumoral Tissue Is Related to Tumor-Associated Epilepsy. Epilepsia 53 (1), 58-66. doi:10.1111/j. 1528-1167.2011.03306.x

DeJesus-Hernandez, M., Mackenzie, I. R., Boeve, B. F., Boxer, A. L., Baker, M., Rutherford, N. J., et al. (2011). Expanded GGGGCC Hexanucleotide Repeat in Noncoding Region of C9ORF72 Causes Chromosome 9p-Linked FTD and ALS. Neuron 72 (2), 245-256. doi:10.1016/j.neuron.2011.09.011

Dhaenens, C.-M., Burnouf, S., Simonin, C., Van Brussel, E., Duhamel, A., Defebvre, L., et al. (2009). A Genetic Variation in the ADORA2A Gene Modifies Age at Onset in Huntington's Disease. Neurobiol. Dis. 35 (3), 474-476. doi:10.1016/j. nbd.2009.06.009

Diamond, M. L., Ritter, A. C., Jackson, E. K., Conley, Y. P., Kochanek, P. M., Boison, D., et al. (2015). Genetic Variation in the Adenosine Regulatory Cycle Is Associated with Posttraumatic Epilepsy Development. Epilepsia 56 (8), 1198-1206. doi:10.1111/epi.13044

Domise, M., Sauvé, F., Didier, S., Caillerez, R., Bégard, S., Carrier, S., et al. (2019). Neuronal AMP-Activated Protein Kinase Hyper-Activation Induces Synaptic Loss by an Autophagy-Mediated Process. Cell Death Dis. 10 (3), 221. doi:10. 1038/s41419-019-1464-x

Donlea, J. M., Alam, M. N., and Szymusiak, R. (2017). Neuronal Substrates of Sleep Homeostasis; Lessons from Flies, Rats and Mice. Curr. Opin. Neurobiol. 44, 228-235. doi:10.1016/j.conb.2017.05.003

Dos Santos-Rodrigues, A., Grañé-Boladeras, N., Bicket, A., and Coe, I. R. (2014). Nucleoside Transporters in the Purinome. Neurochem. Int. 73, 229-237. doi:10. 1016/j.neuint.2014.03.014

Duarte, R. R. R., Bachtel, N. D., Côtel, M.-C., Lee, S. H., Selvackadunco, S., Watson, I. A., et al. (2019). The Psychiatric Risk Gene NT5C2 Regulates Adenosine Monophosphate-Activated Protein Kinase Signaling and Protein Translation in Human Neural Progenitor Cells. Biol. Psychiatry 86, 120-130. doi:10.1016/j. biopsych.2019.03.977

Duarte, R. R. R., Troakes, C., Nolan, M., Srivastava, D. P., Murray, R. M., and Bray, N. J. (2016). Genome-wide Significant Schizophrenia Risk Variation on Chromosome 10q24 Is Associated with Alteredcis-Regulation ofBORCS7,AS3MT, andNT5C2in the Human Brain. Am. J. Med. Genet. 171, 806-814. doi:10.1002/ajmg.b.32445

Duflot, S., Riera, B., Fernández-Veledo, S., Casadó, V., Norman, R. I., Casado, F. J., et al. (2004). ATP-Sensitive K+ Channels Regulate the Concentrative Adenosine Transporter CNT2 Following Activation by A1 Adenosine Receptors. Mol. Cell. Biol. 24 (7), 2710-2719. doi:10.1128/mcb.24.7.2710-2719.2004

Elsaid, M. F., Ibrahim, K., Chalhoub, N., Elsotouhy, A., El Mudehki, N., and Abdel Aleem, A. (2017). NT5C2 Novel Splicing Variant Expands the Phenotypic Spectrum of Spastic Paraplegia (SPG45): Case Report of a New Member of Thin Corpus Callosum SPG-Subgroup. Bmc Med. Genet. 18, 33. doi:10.1186/s12881017-0395-6

Engel, K., Zhou, M., and Wang, J. (2004). Identification and Characterization of a Novel Monoamine Transporter in the Human Brain. J. Biol. Chem. 279 (48), 50042-50049. doi:10.1074/jbc.M407913200

Farré, X., Guillén-Gómez, E., Sánchez, L., Hardisson, D., Plaza, Y., Lloberas, J., et al. (2004). Expression of the Nucleoside-Derived Drug Transporters hCNT1, hENT1 and hENT2 in Gynecologic Tumors. Int. J. Cancer 112 (6), 959-966. doi:10.1002/ijc.20524

Ferrante, A., Martire, A., Pepponi, R., Varani, K., Vincenzi, F., Ferraro, L., et al. (2014). Expression, Pharmacology and Functional Activity of Adenosine A1 Receptors in Genetic Models of Huntington's Disease. Neurobiol. Dis. 71, 193-204. doi:10.1016/j.nbd.2014.08.013

Ferré, S., and Ciruela, F. (2019). Functional and Neuroprotective Role of Striatal Adenosine A2AReceptor Heterotetramers. J. Caffeine Adenosine Res. 9 (3), 89-97. doi:10.1089/caff.2019.0008
Flinn, A. M., and Gennery, A. R. (2018). Adenosine Deaminase Deficiency: a Review. Orphanet J. Rare Dis. 13 (1), 65. doi:10.1186/s13023-018-0807-5

Floare, M.-L., and Allen, S. P. (2020). Why TDP-43? Why Not? Mechanisms of Metabolic Dysfunction in Amyotrophic Lateral Sclerosis. J. Exp. Neurosci. 15, 263310552095730. doi:10.1177/2633105520957302

Ford, H., Jr., Dai, F., Mu, L., Siddiqui, M. A., Nicklaus, M. C., Anderson, L., et al. (2000). Adenosine Deaminase Prefers a Distinct Sugar Ring Conformation for Binding and Catalysis: Kinetic and Structural Studies. Biochemistry 39 (10), 2581-2592. doi:10.1021/bi992112c

Franco, R., Casadó, V., Ciruela, F., Saura, C., Mallol, J., Canela, E. I., et al. (1997). Cell Surface Adenosine Deaminase: Much More Than an Ectoenzyme. Prog. Neurobiol. 52 (4), 283-294. doi:10.1016/s0301-0082(97)00013-0

Fredholm, B. B., and Svenningsson, P. (2020). Why Target Brain Adenosine Receptors? A Historical Perspective. Parkinsonism Relat. Disord. 80 (Suppl. 1), S3-S6. doi:10.1016/j.parkreldis.2020.09.027

Gandelman, M., Peluffo, H., Beckman, J. S., Cassina, P., and Barbeito, L. (2010). Extracellular ATP and the P2X7 Receptor in Astrocyte-Mediated Motor Neuron Death: Implications for Amyotrophic Lateral Sclerosis. J. Neuroinflammation 7, 33. doi:10.1186/1742-2094-7-33

Garcia-Gil, M., Camici, M., Allegrini, S., Pesi, R., Petrotto, E., and Tozzi, M. (2018). Emerging Role of Purine Metabolizing Enzymes in Brain Function and Tumors. Int. J. Mol. Sci. 19 (11), 3598. doi:10.3390/ijms19113598

Garcia-Gil, M., Pesi, R., Perna, S., Allegrini, S., Giannecchini, M., Camici, M., et al. (2003). 5'-aminoimidazole-4-carboxamide Riboside Induces Apoptosis in Human Neuroblastoma Cells. Neuroscience 117 (4), 811-820. doi:10.1016/ s0306-4522(02)00836-9

Gebril, H. M., Rose, R. M., Gesese, R., Emond, M. P., Huo, Y., Aronica, E., et al. (2020). Adenosine Kinase Inhibition Promotes Proliferation of Neural Stem Cells after Traumatic Brain Injury. Brain Commun. 2 (1), fcaa017. doi:10.1093/ braincomms/fcaa017

Gertz, M., Nguyen, G. T. T., Fischer, F., Suenkel, B., Schlicker, C., Fränzel, B., et al. (2012). A Molecular Mechanism for Direct Sirtuin Activation by Resveratrol. PLoS One 7 (11), e49761. doi:10.1371/journal.pone.0049761

Gibson, K. M., Morishita, K. A., Dancey, P., Moorehead, P., Drögemöller, B., Han, X., et al. (2019). Identification of Novel Adenosine Deaminase 2 Gene Variants and Varied Clinical Phenotype in Pediatric Vasculitis. Arthritis Rheumatol. 71 (10), 1747-1755. doi:10.1002/art.40913

Glaser, T., Andrejew, R., Oliveira-Giacomelli, Á., Ribeiro, D. E., Bonfim Marques, L., Ye, Q., et al. (2020). Purinergic Receptors in Basal Ganglia Diseases: Shared Molecular Mechanisms between Huntington's and Parkinson's Disease. Neurosci. Bull. 36 (11), 1299-1314. doi:10.1007/s12264-020-00582-8

Gonçalves, F. Q., Lopes, J. P., Silva, H. B., Lemos, C., Silva, A. C., Gonçalves, N., et al. (2019). Synaptic and Memory Dysfunction in a $\beta$-amyloid Model of Early Alzheimer's Disease Depends on Increased Formation of ATP-Derived Extracellular Adenosine. Neurobiol. Dis. 132, 104570. doi:10.1016/j.nbd.2019. 104570

Gowans, G. J., Hawley, S. A., Ross, F. A., and Hardie, D. G. (2013). AMP Is a True Physiological Regulator of AMP-Activated Protein Kinase by Both Allosteric Activation and Enhancing Net Phosphorylation. Cell Metab. 18 (4), 556-566. doi:10.1016/j.cmet.2013.08.019

Gracia, E., Cortés, A., Meana, J. J., García-Sevilla, J., Herhsfield, M. S., Canela, E. I., et al. (2008). Human Adenosine Deaminase as an Allosteric Modulator of Human Aladenosine Receptor: Abolishment of Negative Cooperativity for [3H](R)-pia Binding to the Caudate Nucleus. J. Neurochem. 107 (1), 161-170. doi:10.1111/j.1471-4159.2008.05602.x

Gracia, E., Pérez-Capote, K., Moreno, E., Barkešová, J., Mallol, J., Lluís, C., et al. (2011). A2A Adenosine Receptor Ligand Binding and Signalling Is Allosterically Modulated by Adenosine Deaminase. Biochem. J. 435 (3), 701-709. doi:10.1042/BJ20101749

Guidolin, D., Marcoli, M., Tortorella, C., Maura, G., and Agnati, L. F. (2020). Adenosine A2A-Dopamine D2 Receptor-Receptor Interaction in Neurons and Astrocytes: Evidence and Perspectives. Prog. Mol. Biol. Transl Sci. 169, 247-277. doi:10.1016/bs.pmbts.2019.11.004

Guillén-Gomez, E., Calbet, M., Casado, J., de Lecea, L., Soriano, E., PastorAnglada, M., et al. (2004). Distribution of CNT2 and ENT1 Transcripts in Rat Brain: Selective Decrease of CNT2 mRNA in the Cerebral Cortex of SleepDeprived Rats. J. Neurochem. 90 (4), 883-893. doi:10.1111/j.1471-4159.2004. 02545.x 
Guitart, X., Bonaventura, J., Rea, W., Orrú, M., Cellai, L., Dettori, I., et al. (2016). Equilibrative Nucleoside Transporter ENT1 as a Biomarker of Huntington Disease. Neurobiol. Dis. 96, 47-53. doi:10.1016/j.nbd.2016.08.013

Hamilton, J., Brustovetsky, T., Sridhar, A., Pan, Y., Cummins, T. R., Meyer, J. S., et al. (2020). Energy Metabolism and Mitochondrial Superoxide Anion Production in Pre-symptomatic Striatal Neurons Derived from HumanInduced Pluripotent Stem Cells Expressing Mutant Huntingtin. Mol. Neurobiol. 57 (2), 668-684. doi:10.1007/s12035-019-01734-2

Hardie, D. G., and Hawley, S. A. (2001). AMP-activated Protein Kinase: the Energy Charge Hypothesis Revisited. Bioessays 23 (12), 1112-1119. doi:10.1002/bies. 10009

Hardie, D. G., Ross, F. A., and Hawley, S. A. (2012). AMPK: a Nutrient and Energy Sensor that Maintains Energy Homeostasis. Nat. Rev. Mol. Cell Biol. 13 (4), 251-262. doi:10.1038/nrm3311

Hervás, D., Fornés-Ferrer, V., Gómez-Escribano, A. P., Sequedo, M. D., Peiró, C., Millán, J. M., et al. (2017). Metformin Intake Associates with Better Cognitive Function in Patients with Huntington's Disease. PLoS One 12 (6), e0179283. doi:10.1371/journal.pone.0179283

HD iPSC Consortium (2020). Bioenergetic Deficits in Huntington's Disease iPSCDerived Neural Cells and Rescue with Glycolytic Metabolites. Hum. Mol. Genet. 29 (11), 1757-1771. doi:10.1093/hmg/ddy430

Ho, S. Y., Chen, I. C., Chang, K. C., Lin, H. R., Tsai, C. W., Lin, C. J., et al. (2020). Equilibrative Nucleoside Transporters-1 Inhibitors Act as Anti-epileptic Agents by Inhibiting Glutamatergic Transmission. Front. Neurosci. 14, 610898. doi:10. 3389/fnins.2020.610898

Hönig, M., Albert, M. H., Schulz, A., Sparber-Sauer, M., Schütz, C., Belohradsky, B., et al. (2007). Patients with Adenosine Deaminase Deficiency Surviving after Hematopoietic Stem Cell Transplantation Are at High Risk of CNS Complications. Blood 109 (8), 3595-3602. doi:10.1182/blood-2006-07-034678

Huang, H., Wang, J., Zhang, J., Luo, Z., Li, D., Qiu, X., et al. (2017). Nitrobenzylthioinosine Mimics Adenosine to Attenuate the Epileptiform Discharge of Hippocampal Neurons from Epileptic Rats. Oncotarget 8 (22), 35573-35582. doi:10.18632/oncotarget.16012

Huang, J., He, Y., Chen, M., Du, J., Li, G., Li, S., et al. (2015). Adenosine Deaminase and Adenosine Kinase Expression in Human Glioma and Their Correlation with Glioma-Associated Epilepsy. Mol. Med. Rep. 12 (5), 6509-6516. doi:10. 3892/mmr.2015.4285

Huber-Ruano, I., Pinilla-Macua, I., Torres, G., Casado, F. J., and Pastor-Anglada, M. (2010). Link between High-Affinity Adenosine Concentrative Nucleoside Transporter-2 (CNT2) and Energy Metabolism in Intestinal and Liver Parenchymal Cells. J. Cell. Physiol. 225 (2), 620-630. doi:10.1002/jcp.22254

Hunsucker, S. A., Spychala, J., and Mitchell, B. S. (2001). Human Cytosolic 5'Nucleotidase I. J. Biol. Chem. 276 (13), 10498-10504. doi:10.1074/jbc. $\mathrm{m} 011218200$

Huynh, M. K. Q., Kinyua, A. W., Yang, D. J., and Kim, K. W. (2016). Hypothalamic AMPK as a Regulator of Energy Homeostasis. Neural Plasticity 2016, 1-12. doi:10.1155/2016/2754078

Illes, P., Rubini, P., Ulrich, H., Zhao, Y., and Tang, Y. (2020). Regulation of Microglial Functions by Purinergic Mechanisms in the Healthy and Diseased CNS. Cells 9 (5), 1108. doi:10.3390/cells9051108

Imfeld, P., Bodmer, M., Jick, S. S., and Meier, C. R. (2012). Metformin, Other Antidiabetic Drugs, and Risk of Alzheimer's Disease: a Population-Based CaseControl Study. J. Am. Geriatr. Soc. 60 (5), 916-921. doi:10.1111/j.1532-5415. 2012.03916.x

Ipata, P. L., Camici, M., Micheli, V., and Tozz, M. G. (2011). Metabolic Network of Nucleosides in the Brain. Curr. Top. Med. Chem. 11 (8), 909-922. doi:10.2174/ 156802611795347555

Jacobson, K. A., Tosh, D. K., Jain, S., and Gao, Z.-G. (2019). Historical and Current Adenosine Receptor Agonists in Preclinical and Clinical Development. Front. Cell. Neurosci. 13, 124. doi:10.3389/fncel.2019.00124

Jakovljevic, M., Lavrnja, I., Bozic, I., Milosevic, A., Bjelobaba, I., Savic, D., et al. (2019). Induction of NTPDase1/CD39 by Reactive Microglia and Macrophages Is Associated with the Functional State during EAE. Front. Neurosci. 13, 410. doi: 10.3389/fnins.2019.00410

James, S. J., Melnyk, S., Pogribna, M., Pogribny, I. P., and Caudill, M. A. (2002). Elevation in S-Adenosylhomocysteine and DNA Hypomethylation: Potential Epigenetic Mechanism for Homocysteine-Related Pathology. J. Nutr. 132 (8 Suppl. 1), 2361S-2366S. doi:10.1093/jn/132.8.2361S
Jin, J., Gu, H., Anders, N. M., Ren, T., Jiang, M., Tao, M., et al. (2016). Metformin Protects Cells from Mutant Huntingtin Toxicity through Activation of AMPK and Modulation of Mitochondrial Dynamics. Neuromol Med. 18 (4), 581-592. doi:10.1007/s12017-016-8412-z

Ju, T.-C., Chen, H.-M., Lin, J.-T., Chang, C.-P., Chang, W.-C., Kang, J.-J., et al. (2011). Nuclear Translocation of AMPK-al Potentiates Striatal Neurodegeneration in Huntington's Disease. J. Cell Biol. 194 (2), 209-227. doi: $10.1083 /$ jcb. 201105010

Kao, Y.-H., Lin, M.-S., Chen, C.-M., Wu, Y.-R., Chen, H.-M., Lai, H.-L., et al. (2017). Targeting ENT1 and Adenosine Tone for the Treatment of Huntington's Disease. Hum. Mol. Genet. 26 (3), ddw402-478. doi:10.1093/ hmg/ddw402

Kiese, K., Jablonski, J., Boison, D., and Kobow, K. (2016). Dynamic Regulation of the Adenosine Kinase Gene during Early Postnatal Brain Development and Maturation. Front. Mol. Neurosci. 9, 99. doi:10.3389/fnmol.2016.00099

Király, K., Kozsurek, M., Lukácsi, E., Barta, B., Alpár, A., Balázsa, T., et al. (2018). Glial Cell Type-specific Changes in Spinal Dipeptidyl Peptidase 4 Expression and Effects of its Inhibitors in Inflammatory and Neuropatic Pain. Sci. Rep. 8 (1), 3490. doi:10.1038/s41598-018-21799-8

Klein, K., Kullak-Ublick, G. A., Wagner, M., Trauner, M., and Eloranta, J. J. (2009). Hepatocyte Nuclear Factor-4a and Bile Acids Regulate Human Concentrative Nucleoside Transporter-1 Gene Expression. Am. J. Physiol.-Gastrointestinal Liver Physiol. 296 (4), G936-G947. doi:10.1152/ajpgi.90678.2008

Kola, B. (2008). Role of AMP-Activated Protein Kinase in the Control of Appetite. J. Neuroendocrinol 20 (7), 942-951. doi:10.1111/j.1365-2826.2008.01745.x

Kortüm, F., Jamra, R. A., Alawi, M., Berry, S. A., Borck, G., Helbig, K. L., et al. (2018). Clinical and Genetic Spectrum of AMPD2-Related Pontocerebellar Hypoplasia Type 9. Eur. J. Hum. Genet. 26 (5), 695-708. doi:10.1038/s41431-018-0098-2

Kuptanon, C., Srichomthong, C., Ittiwut, C., Wechapinan, T., Sri-Udomkajorn, S., Iamopas, O., et al. (2019). Whole Exome Sequencing Revealed Mutations in FBXL4, UNC80, and ADK in Thai Patients with Severe Intellectual Disabilities. Gene 696, 21-27. doi:10.1016/j.gene.2019.01.049

Laughlin, R. E., Grant, T. L., Williams, R. W., and Jentsch, J. D. (2011). Genetic Dissection of Behavioral Flexibility: Reversal Learning in Mice. Biol. Psychiatry 69 (11), 1109-1116. doi:10.1016/j.biopsych.2011.01.014

Lavrnja, I., Laketa, D., Savic, D., Bozic, I., Bjelobaba, I., Pekovic, S., et al. (2015). Expression of a Second Ecto- $5^{\prime}$-Nucleotidase Variant besides the Usual Protein in Symptomatic Phase of Experimental Autoimmune Encephalomyelitis. J. Mol. Neurosci. 55 (4), 898-911. doi:10.1007/s12031-014-0445-x

Lazarus, M., Oishi, Y., Bjorness, T. E., and Greene, R. W. (2019). Gating and the Need for Sleep: Dissociable Effects of Adenosine A1 and A2A Receptors. Front. Neurosci. 13, 740. doi:10.3389/fnins.2019.00740

Lee, C. C., Chang, C. P., Lin, C. J., Lai, H. L., Kao, Y. H., Cheng, S. J., et al. (2018). Adenosine Augmentation Evoked by an ENT1 Inhibitor Improves Memory Impairment and Neuronal Plasticity in the APP/PS1 Mouse Model of Alzheimer's Disease. Mol. Neurobiol. 55 (12), 8936-8952. doi:10.1007/ s12035-018-1030-Z

Lee, C. F., and Chern, Y. (2014). Adenosine Receptors and Huntington's Disease. Int. Rev. Neurobiol. 119, 195-232. doi:10.1016/B978-0-12-801022-8.00010-6

Li, T., Quan Lan, J., Fredholm, B. B., Simon, R. P., and Boison, D. (2007). Adenosine Dysfunction in Astrogliosis: Cause for Seizure Generation?. Neuron Glia Biol. 3 (4), 353-366. doi:10.1017/S1740925X0800015X

Li, T., Ren, G., Lusardi, T., Wilz, A., Lan, J. Q., Iwasato, T., et al. (2008). Adenosine Kinase Is a Target for the Prediction and Prevention of Epileptogenesis in Mice. J. Clin. Invest. 118 (2), 571-582. doi:10.1172/JCI33737

Li, W., Silva, H. B., Real, J., Wang, Y.-M., Rial, D., Li, P., et al. (2015). Inactivation of Adenosine A2A Receptors Reverses Working Memory Deficits at Early Stages of Huntington's Disease Models. Neurobiol. Dis. 79, 70-80. doi:10.1016/j.nbd. 2015.03.030

Liu, H., Xu, Y., and Hu, F. (2020). AMPK in the Ventromedial Nucleus of the Hypothalamus: A Key Regulator for Thermogenesis. Front. Endocrinol. 11, 578830. doi:10.3389/fendo.2020.578830

Luan, G., Gao, Q., Guan, Y., Zhai, F., Zhou, J., Liu, C., et al. (2013). Upregulation of Adenosine Kinase in Rasmussen Encephalitis. J. Neuropathol. Exp. Neurol. 72 (11), 1000-1008. doi:10.1097/01.jnen.0000435369.39388.5c

Luan, G., Gao, Q., Zhai, F., Zhou, J., Liu, C., Chen, Y., et al. (2015). Adenosine Kinase Expression in Cortical Dysplasia with Balloon Cells. J. Neuropathol. Exp. Neurol. 74 (2), 132-147. doi:10.1097/NEN.0000000000000156 
Lusardi, T. A., Akula, K. K., Coffman, S. Q., Ruskin, D. N., Masino, S. A., and Boison, D. (2015). Ketogenic Diet Prevents Epileptogenesis and Disease Progression in Adult Mice and Rats. Neuropharmacology 99, 500-509. doi:10.1016/j.neuropharm.2015.08.007

Ma, T. C., Buescher, J. L., Oatis, B., Funk, J. A., Nash, A. J., Carrier, R. L., et al. (2007). Metformin therapy in a transgenic mouse model of Huntington's disease. Neurosci. Lett. 411 (2), 98-103. doi:10.1016/j.neulet.2006.10.039

Mahnke-Zizelman, D. K., and Sabina, R. L. (1992). Cloning of Human AMP Deaminase Isoform E cDNAs. Evidence for a Third AMPD Gene Exhibiting Alternatively Spliced 5'-exons. J. Biol. Chem. 267 (29), 20866-20877. doi:10. 1016/s0021-9258(19)36768-7

Manalo, J. M., Liu, H., Ding, D., Hicks, J., Sun, H., Salvi, R., et al. (2020). Adenosine A2B Receptor: A Pathogenic Factor and a Therapeutic Target for Sensorineural Hearing Loss. FASEB j. 34 (12), 15771-15787. doi:10.1096/fj.202000939R

Marsh, A. P. L., Lukic, V., Pope, K., Bromhead, C., Tankard, R., Ryan, M. M., et al. (2015). Complete Callosal Agenesis, Pontocerebellar Hypoplasia, and Axonal Neuropathy Due to AMPD2 Loss. Neurol. Genet. 1 (2), e16. doi:10.1212/NXG. 0000000000000014

Masino, S. A., Kawamura, M., Jr., and Ruskin, D. N. (2014). Adenosine Receptors and Epilepsy. Int. Rev. Neurobiol. 119, 233-255. doi:10.1016/B978-0-12801022-8.00011-8

Masino, S. A., Li, T., Theofilas, P., Sandau, U. S., Ruskin, D. N., Fredholm, B. B., et al. (2011). A Ketogenic Diet Suppresses Seizures in Mice through Adenosine A1 Receptors. J. Clin. Invest. 121 (7), 2679-2683. doi:10.1172/JCI57813

Matusch, A., Saft, C., Elmenhorst, D., Kraus, P. H., Gold, R., Hartung, H.-P., et al. (2014). Cross Sectional PET Study of Cerebral Adenosine A1 Receptors in Premanifest and Manifest Huntington's Disease. Eur. J. Nucl. Med. Mol. Imaging 41 (6), 1210-1220. doi:10.1007/s00259-014-2724-8

Medina-Pulido, L., Molina-Arcas, M., Justicia, C., Soriano, E., Burgaya, F., Planas, A. M., et al. (2013). Hypoxia and P1 Receptor Activation Regulate the HighAffinity Concentrative Adenosine Transporter CNT2 in Differentiated Neuronal PC12 Cells. Biochem. J. 454 (3), 437-445. doi:10.1042/BJ20130231

Mejzini, R., Flynn, L. L., Pitout, I. L., Fletcher, S., Wilton, S. D., and Akkari, P. A. (2019). ALS Genetics, Mechanisms, and Therapeutics: Where Are We Now?. Front. Neurosci. 13, 1310. doi:10.3389/fnins.2019.01310

Melani, A., Pugliese, A. M., and Pedata, F. (2014). Adenosine Receptors in Cerebral Ischemia. Int. Rev. Neurobiol. 119, 309-348. doi:10.1016/B978-0-12-801022-8.00013-1

Meng, F., Guo, Z., Hu, Y., Mai, W., Zhang, Z., Zhang, B., et al. (2019). CD73derived Adenosine Controls Inflammation and Neurodegeneration by Modulating Dopamine Signalling. Brain 142 (3), 700-718. doi:10.1093/ brain/awy351

Meyts, I., and Aksentijevich, I. (2018). Deficiency of Adenosine Deaminase 2 (DADA2): Updates on the Phenotype, Genetics, Pathogenesis, and Treatment. J. Clin. Immunol. 38 (5), 569-578. doi:10.1007/s10875-018-0525-8

Moens, L., Hershfield, M., Arts, K., Aksentijevich, I., and Meyts, I. (2019). Human Adenosine Deaminase 2 Deficiency: A Multi-Faceted Inborn Error of Immunity. Immunol. Rev. 287 (1), 62-72. doi:10.1111/imr.12722

Moreno, E., Canet, J., Gracia, E., Lluís, C., Mallol, J., Canela, E. I., et al. (2018). Molecular Evidence of Adenosine Deaminase Linking Adenosine A2A Receptor and CD26 Proteins. Front. Pharmacol. 9, 106. doi:10.3389/fphar. 2018.00106

Mori, A. (2020). How Do Adenosine A2A Receptors Regulate Motor Function?. Parkinsonism Relat. Disord. 80 (Suppl. 1), S13-S20. doi:10.1016/j.parkreldis. 2020.09 .025

Morisaki, T., Sabina, R. L., and Holmes, E. W. (1990). Adenylate Deaminase. A Multigene Family in Humans and Rats. J. Biol. Chem. 265 (20), 11482-11486. doi:10.1016/s0021-9258(19)38422-4

Morote-Garcia, J. C., Rosenberger, P., Nivillac, N. M., Coe, I. R., and Eltzschig, H. K. (2009). Hypoxia-inducible Factor-dependent Repression of Equilibrative Nucleoside Transporter 2 Attenuates Mucosal Inflammation during Intestinal Hypoxia. Gastroenterology 136 (2), 607-618. doi:10.1053/j.gastro.2008.10.037

Naes, S. M., Ab-Rahim, S., Mazlan, M., and Abdul Rahman, A. (2020). Equilibrative Nucleoside Transporter 2: Properties and Physiological Roles. Biomed. Res. Int. 2020, 1-8. doi:10.1155/2020/5197626

Nam, H. W., Hinton, D. J., Kang, N. Y., Kim, T., Lee, M. R., Oliveros, A., et al. (2013). Adenosine Transporter ENT1 Regulates the Acquisition of GoalDirected Behavior and Ethanol Drinking through A2A Receptor in the
Dorsomedial Striatum. J. Neurosci. 33 (10), 4329-4338. doi:10.1523/ JNEUROSCI.3094-12.2013

Naseer, M. I., Abdulkareem, A. A., Pushparaj, P. N., Bibi, F., and Chaudhary, A. G. (2020). Exome Analysis Identified Novel Homozygous Splice Site Donor Alteration in NT5C2 Gene in a Saudi Family Associated with Spastic Diplegia Cerebral Palsy, Developmental Delay, and Intellectual Disability. Front. Genet. 11, 14. doi:10.3389/fgene.2020.00014

Naula, C. M., Logan, F. M., Wong, P. E., Barrett, M. P., and Burchmore, R. J. (2010). A Glucose Transporter Can Mediate Ribose Uptake. J. Biol. Chem. 285 (39), 29721-29728. doi:10.1074/jbc.M110.106815

Navon Elkan, P., Pierce, S. B., Segel, R., Walsh, T., Barash, J., Padeh, S., et al. (2014). Mutant Adenosine Deaminase 2 in a Polyarteritis Nodosa Vasculopathy. $N$. Engl. J. Med. 370 (10), 921-931. doi:10.1056/NEJMoa1307362

Nedeljkovic, N., Bjelobaba, I., Subasic, S., Lavrnja, I., Pekovic, S., Stojkov, D., et al. (2006). Up-regulation of Ectonucleotidase Activity after Cortical Stab Injury in Rats. Cell Biol. Int. 30 (6), 541-546. doi:10.1016/j.cellbi.2006.03.001

Nedeljkovic, N. (2019). Complex Regulation of Ecto-5'-nucleotidase/CD73 and A2AR-mediated Adenosine Signaling at Neurovascular Unit: A Link between Acute and Chronic Neuroinflammation. Pharmacol. Res. 144, 99-115. doi:10. 1016/j.phrs.2019.04.007

Ng, S. K., Higashimori, H., Tolman, M., and Yang, Y. (2015). Suppression of Adenosine 2a Receptor (A2aR)-Mediated Adenosine Signaling Improves Disease Phenotypes in a Mouse Model of Amyotrophic Lateral Sclerosis. Exp. Neurol. 267, 115-122. doi:10.1016/j.expneurol.2015.03.004

Ng, T. P., Feng, L., Yap, K. B., Lee, T. S., Tan, C. H., and Winblad, B. (2014). Longterm Metformin Usage and Cognitive Function Among Older Adults with Diabetes. Jad 41 (1), 61-68. doi:10.3233/JAD-131901

Niechi, I., Uribe-Ojeda, A., Erices, J. I., Torres, Á., Uribe, D., Rocha, J. D., et al. (2019). Adenosine Depletion as A New Strategy to Decrease Glioblastoma Stem-like Cells Aggressiveness. Cells 8 (11), 1353. doi:10.3390/cells8111353

Nofech-Mozes, Y., Blaser, S. I., Kobayashi, J., Grunebaum, E., and Roifman, C. M. (2007). Neurologic Abnormalities in Patients with Adenosine Deaminase Deficiency. Pediatr. Neurol. 37 (3), 218-221. doi:10.1016/j.pediatrneurol. 2007.03.011

Novarino, G., Fenstermaker, A. G., Zaki, M. S., Hofree, M., Silhavy, J. L., Heiberg, A. D., et al. (2014). Exome Sequencing Links Corticospinal Motor Neuron Disease to Common Neurodegenerative Disorders. Science 343, 506-511. doi:10.1126/science. 1247363

Osborne, D. M., Sandau, U. S., Jones, A. T., Vander Velden, J. W., Weingarten, A. M., Etesami, N., et al. (2018). Developmental Role of Adenosine Kinase for the Expression of Sex-dependent Neuropsychiatric Behavior. Neuropharmacology 141, 89-97. doi:10.1016/j.neuropharm.2018.08.025

Parkinson, F. E., Damaraju, V. L., Graham, K., Yao, S. Y., Baldwin, S. A., Cass, C. E., et al. (2011). Molecular Biology of Nucleoside Transporters and Their Distributions and Functions in the Brain. Curr. Top. Med. Chem. 11 (8), 948-972. doi:10.2174/156802611795347582

Pastor-Anglada, M., and Pérez-Torras, S. (2018). Emerging Roles of Nucleoside Transporters. Front. Pharmacol. 9, 606. doi:10.3389/fphar.2018.00606

Peixoto, C. A., Oliveira, W. H. d., Araújo, S. M. d. R., and Nunes, A. K. S. (2017). AMPK Activation: Role in the Signaling Pathways of Neuroinflammation and Neurodegeneration. Exp. Neurol. 298 (Pt A), 31-41. doi:10.1016/j.expneurol. 2017.08.013

Pereira-Figueiredo, D., Nascimento, A. A., Cunha-Rodrigues, M. C., Brito, R., and Calaza, K. C. (2021). Caffeine and Its Neuroprotective Role in Ischemic Events: A Mechanism Dependent on Adenosine Receptors. Cell Mol Neurobiol. doi:10. 1007/s10571-021-01077-4

Perera, N. D., and Turner, B. J. (2016). AMPK Signalling and Defective Energy Metabolism in Amyotrophic Lateral Sclerosis. Neurochem. Res. 41, 544-553. doi:10.1007/s11064-015-1665-3

Pérez-Torras, S., Vidal-Pla, A., Cano-Soldado, P., Huber-Ruano, I., Mazo, A., and Pastor-Anglada, M. (2013). Concentrative Nucleoside Transporter 1 (hCNT1) Promotes Phenotypic Changes Relevant to Tumor Biology in a Translocationindependent Manner. Cell Death Dis. 4, e648. doi:10.1038/cddis.2013.173

Perrier, S. P., Gleizes, M., Fonta, C., and Nowak, L. G. (2019). Effect of Adenosine on Short-Term Synaptic Plasticity in Mouse Piriform Cortex In Vitro: Adenosine Acts as a High-Pass Filter. Physiol. Rep. 7 (3), e13992. doi:10. $14814 /$ phy2.13992 
Pesi, R., Allegrini, S., Balestri, F., Garcia-Gil, M., Cividini, F., Colombaioni, L., et al. (2021). Cytosolic 5'-Nucleotidase II Is a Sensor of Energy Charge and Oxidative Stress: A Possible Function as Metabolic Regulator. Cells 10 (1), 182. doi:10. 3390/cells10010182

Pesi, R., Micheli, V., Jacomelli, G., Peruzzi, L., Camici, M., Garcia-Gil, M., et al. (2000). Cytosolic $5^{\prime}$-nucleotidase Hyperactivity in Erythrocytes of LeschNyhan Syndrome Patients. Neuroreport 11 (9), 1827-1831. doi:10.1097/ 00001756-200006260-00006

Pesi, R., Petrotto, E., Colombaioni, L., Allegrini, S., Garcia-Gil, M., Camici, M., et al. (2018). Cytosolic 5'-Nucleotidase II Silencing in a Human Lung Carcinoma Cell Line Opposes Cancer Phenotype with a Concomitant Increase in P53 Phosphorylation. Int. J. Mol. Sci. 19 (7), 2115. doi:10.3390/ijms19072115

Pesi, R., Turriani, M., Allegrini, S., Scolozzi, C., Camici, M., Ipata, P. L., et al. (1994). The Bifunctional Cytosolic 5'-Nucleotidase: Regulation of the Phosphotransferase and Nucleotidase Activities. Arch. Biochem. Biophys. 312 (1), 75-80. doi:10.1006/abbi.1994.1282

Poppe, D., Doerr, J., Schneider, M., Wilkens, R., Steinbeck, J. A., Ladewig, J., et al. (2018). Genome Editing in Neuroepithelial Stem Cells to Generate Human Neurons with High Adenosine-Releasing Capacity. STEM CELLS Transl. Med. 7 (6), 477-486. doi:10.1002/sctm.16-0272

Porkka-Heiskanen, T., Strecker, R. E., Thakkar, M., Bjorkum, A. A., Greene, R. W., and McCarley, R. W. (1997). Adenosine: a Mediator of the Sleep-Inducing Effects of Prolonged Wakefulness. Science 276 (5316), 1265-1268. doi:10.1126/ science.276.5316.1265

Potenza, R. L., Armida, M., Ferrante, A., Pèzzola, A., Matteucci, A., Puopolo, M., et al. (2013). Effects of Chronic Caffeine Intake in a Mouse Model of Amyotrophic Lateral Sclerosis. J. Neurosci. Res. 91 (4), 585-592. doi:10. $1002 /$ jnr. 23185

Quezada, C., Garrido, W., Oyarzún, C., Fernández, K., Segura, R., Melo, R., et al. (2013). 5'-ectonucleotidase Mediates Multiple-Drug Resistance in Glioblastoma Multiforme Cells. J. Cell. Physiol. 228 (3), 602-608. doi:10. $1002 /$ jcp. 24168

Rahman, A. (2009). The Role of Adenosine in Alzheimers Disease. Cn 7 (3), 207-216. doi:10.2174/157015909789152119

Renton, A. E., Majounie, E., Waite, A., Simón-Sánchez, J., Rollinson, S., Gibbs, J. R., et al. (2011). A Hexanucleotide Repeat Expansion in C9ORF72 Is the Cause of Chromosome 9p21-Linked ALS-FTD. Neuron 72 (2), 257-268. doi:10.1016/j. neuron.2011.09.010

Reyes, G., Nivillac, N. M. I., Karim, M. Z., Desouza, L., Siu, K. W. M., and Coe, I. R. (2011). The Equilibrative Nucleoside Transporter (ENT1) Can Be Phosphorylated at Multiple Sites by PKC and PKA. Mol. Membr. Biol. 28 (6), 412-426. doi:10.3109/09687688.2011.604861

Rietveld, A., van den Hoogen, L. L., Bizzaro, N., Blokland, S. L. M., Dähnrich, C., Gottenberg, J.-E., et al. (2018). Autoantibodies to Cytosolic 5'-Nucleotidase 1A in Primary Sjögren's Syndrome and Systemic Lupus Erythematosus. Front. Immunol. 9, 1200. doi:10.3389/fimmu.2018.01200

Rodrigues, R. J., Tomé, A. R., and Cunha, R. A. (2015). ATP as a Multi-Target Danger Signal in the Brain. Front. Neurosci. 9, 148. doi:10.3389/fnins.2015. 00148

Rogers, M. H., Lwin, R., Fairbanks, L., Gerritsen, B., and Gaspar, H. B. (2001). Cognitive and Behavioral Abnormalities in Adenosine Deaminase Deficient Severe Combined Immunodeficiency. J. Pediatr. 139 (1), 44-50. doi:10.1067/ mpd.2001.115023

Rosen, D. R., Siddique, T., Patterson, D., Figlewicz, D. A., Sapp, P., Hentati, A., et al. (1993). Mutations in Cu/Zn Superoxide Dismutase Gene Are Associated with Familial Amyotrophic Lateral Sclerosis. Nature 362 (6415), 59-62. doi:10.1038/ $362059 \mathrm{a} 0$

Rosso, P., Fioramonti, M., Fracassi, A., Marangoni, M., Taglietti, V., Siteni, S., et al. (2016). AMPK in the Central Nervous System: Physiological Roles and Pathological Implications. Res. Rep. Biol. 7, 1-13. doi:10.2147/Rrb.S90858

Rothstein, J. D. (2009). Current Hypotheses for the Underlying Biology of Amyotrophic Lateral Sclerosis. Ann. Neurol. 65 (Suppl. 1), S3-S9. doi:10. 1002/ana.21543

Ruby, C. L., Walker, D. L., An, J., Kim, J., and Choi, D. S. (2011). Sex-Specific Regulation of Depression, Anxiety-like Behaviors and Alcohol Drinking in Mice Lacking ENT1. J. Addict. Res. Ther. S4, 004. doi:10.4172/2155-6105. S4-004
Saccucci, P., Arpino, C., Rizzo, R., Gagliano, A., Volzone, A., Lalli, C., et al. (2006). Association of Adenosine Deaminase Polymorphism with Mild Mental Retardation. J. Child. Neurol. 21 (9), 753-756. doi:10.1177/ 08830738060210091201

Sadej, R., Inai, K., Rajfur, Z., Ostapkowicz, A., Kohler, J., Skladanowski, A. C., et al. (2008). Tenascin C Interacts with Ecto-5'-Nucleotidase (eN) and Regulates Adenosine Generation in Cancer Cells. Biochim. Biophys. Acta (Bba) - Mol. Basis Dis. 1782 (1), 35-40. doi:10.1016/j.bbadis.2007.11.001

Sahin, S., Adrovic, A., Barut, K., Baran, S., Tahir Turanli, E., Canpolat, N., et al. (2020). A 9.5-Year-Old Boy with Recurrent Neurological Manifestations and Severe Hypertension, Treated Initially for Polyarteritis Nodosa, Was Subsequently Diagnosed with Adenosine Deaminase Type 2 Deficiency (DADA2) Which Responded to Anti-TNF- $\alpha$. Paediatrics Int. Child Health 40 (1), 65-68. doi:10.1080/20469047.2018.1559495

Sánchez-Melgar, A., Albasanz, J. L., Pallàs, M., and Martín, M. (2020). Adenosine Metabolism in the Cerebral Cortex from Several Mice Models during Aging. Int. J. Mol. Sci. 21 (19), 7300. doi:10.3390/ijms21197300

Sandau, U. S., Colino-Oliveira, M., Jones, A., Saleumvong, B., Coffman, S. Q., Liu, L., et al. (2016). Adenosine Kinase Deficiency in the Brain Results in Maladaptive Synaptic Plasticity. J. Neurosci. 36 (48), 12117-12128. doi:10. 1523/JNEUROSCI.2146-16.2016

Sandau, U. S., Yahya, M., Bigej, R., Friedman, J. L., Saleumvong, B., and Boison, D. (2019). Transient Use of a Systemic Adenosine Kinase Inhibitor Attenuates Epilepsy Development in Mice. Epilepsia 60 (4), 615-625. doi:10.1111/epi. 14674

Sauer, A. V., Hernandez, R. J., Fumagalli, F., Bianchi, V., Poliani, P. L., Dallatomasina, C., et al. (2017). Alterations in the Brain Adenosine Metabolism Cause Behavioral and Neurological Impairment in ADADeficient Mice and Patients. Sci. Rep. 7, 40136. doi:10.1038/srep40136

Schrader, W. P., Pollara, B., and Meuwissen, H. J. (1978). Characterization of the Residual Adenosine Deaminating Activity in the Spleen of a Patient with Combined Immunodeficiency Disease and Adenosine Deaminase Deficiency. Proc. Natl. Acad. Sci. 75 (1), 446-450. doi:10.1073/pnas.75.1.446

Sebastião, A. M., Rei, N., and Ribeiro, J. A. (2018). Amyotrophic Lateral Sclerosis (ALS) and Adenosine Receptors. Front. Pharmacol. 9, 267. doi:10.3389/fphar. 2018.00267

Sebastião, A. M., and Ribeiro, J. A. (2015). Neuromodulation and Metamodulation by Adenosine: Impact and Subtleties upon Synaptic Plasticity Regulation. Brain Res. 1621, 102-113. doi:10.1016/j.brainres.2014.11.008

Shakiba, M., Mahjoub, F., Fazilaty, H., Rezagholizadeh, F., Shakiba, A., Ziadlou, M., et al. (2016). Adenosine Kinase Deficiency with Neurodevelopemental Delay and Recurrent Hepatic Dysfunction: A Case Report. Adv. Rare Dis. 3, 2. doi:10. 12715/ard.2014.3.2

Shen, H.-Y., Lusardi, T. A., Williams-Karnesky, R. L., Lan, J.-Q., Poulsen, D. J., and Boison, D. (2011). Adenosine Kinase Determines the Degree of Brain Injury after Ischemic Stroke in Mice. J. Cereb. Blood Flow Metab. 31 (7), 1648-1659. doi: $10.1038 / \mathrm{jcbfm} .2011 .30$

Shi, Q., Liu, S., Fonseca, V. A., Thethi, T. K., and Shi, L. (2019). Effect of Metformin on Neurodegenerative Disease Among Elderly Adult US Veterans with Type 2 Diabetes Mellitus. BMJ Open 9 (7), e024954. doi:10.1136/bmjopen-2018024954

Simões, A. P., Machado, N. J., Gonçalves, N., Kaster, M. P., Simões, A. T., Nunes, A., et al. (2016). Adenosine A2A Receptors in the Amygdala Control Synaptic Plasticity and Contextual Fear Memory. Neuropsychopharmacol 41 (12), 2862-2871. doi:10.1038/npp.2016.98

Simonin, C., Duru, C., Salleron, J., Hincker, P., Charles, P., Delval, A., et al. (2013). Association between Caffeine Intake and Age at Onset in Huntington's Disease. Neurobiol. Dis. 58, 179-182. doi:10.1016/j.nbd.2013.05.013

Singer, P., McGarrity, S., Shen, H.-Y., Boison, D., and Yee, B. K. (2012). Working Memory and the Homeostatic Control of Brain Adenosine by Adenosine Kinase. Neuroscience 213, 81-92. doi:10.1016/j.neuroscience.2012.03.051

Singer, P., Zhang, C., Boison, D., and Yee, B. K. (2013). Dysregulation of Brain Adenosine Is Detrimental to the Expression of Conditioned Freezing but Not General Pavlovian Learning. Pharmacol. Biochem. Behav. 104, 80-89. doi:10. 1016/j.pbb.2012.12.012

Singgih, E. L., van der Voet, M., Schimmel-Naber, M., Brinkmann, E. L., Schenck, A., and Franke, B. (2021). Investigating Cytosolic 5'-nucleotidase II Family 
Genes as Candidates for Neuropsychiatric Disorders in Drosophila (114/150 Chr). Transl Psychiatry 11 (1), 55. doi:10.1038/s41398-020-01149-x

Skladanowski, A. C., and Newby, A. C. (1990). Partial Purification and Properties of an AMP-specific Soluble 5'-nucleotidase from Pigeon Heart. Biochem. J. 268 (1), 117-122. doi:10.1042/bj2680117

Sozeri, B., Ercan, G., Dogan, O. A., Yıldız, J., Demir, F., and Doğanay, L. (2021). The Same Mutation in a Family with Adenosine Deaminase 2 Deficiency. Rheumatol. Int. 41 (1), 227-233. doi:10.1007/s00296-019-04444-z

Staufner, C., Lindner, M., Dionisi-Vici, C., Freisinger, P., Dobbelaere, D., Douillard, C., et al. (2016). Adenosine Kinase Deficiency: Expanding the Clinical Spectrum and Evaluating Therapeutic Options. J. Inherit. Metab. Dis. 39 (2), 273-283. doi:10.1007/s10545-015-9904-y

Straussberg, R., Onoufriadis, A., Konen, O., Zouabi, Y., Cohen, L., Lee, J. Y. W., et al. (2017). Novel Homozygous Missense Mutation in NT5C2 Underlying Hereditary Spastic Paraplegia SPG45. Am. J. Med. Genet. 173, 3109-3113. doi:10.1002/ajmg.a.38414

Stubbs, G., Litt, M., Lis, E., Jackson, R., Voth, W., Lindberg, A., et al. (1982). Adenosine Deaminase Activity Decreased in Autism. J. Am. Acad. Child Psychiatry 21 (1), 71-74. doi:10.1097/00004583-198201000-00012

Sui, Y., Zhao, Z., Liu, R., Cai, B., and Fan, D. (2014). Adenosine MonophosphateActivated Protein Kinase Activation Enhances Embryonic Neural Stem Cell Apoptosis in a Mouse Model of Amyotrophic Lateral Sclerosis. Neural Regen. Res. 9 (19), 1770-1778. doi:10.4103/1673-5374.143421

Taherzadeh-Fard, E., Saft, C., Wieczorek, S., Epplen, J. T., and Arning, L. (2010). Age at Onset in Huntington's Disease: Replication Study on the Associations of ADORA2A, HAP1 and OGG1. Neurogenetics 11 (4), 435-439. doi:10.1007/ s10048-010-0248-3

Temido-Ferreira, M., Coelho, J. E., Pousinha, P. A., and Lopes, L. V. (2019). Novel Players in the Aging Synapse: Impact on Cognition. J. Caffeine Adenosine Res. 9 (3), 104-127. doi:10.1089/caff.2019.0013

Tescarollo, F. C., Rombo, D. M., DeLiberto, L. K., Fedele, D. E., Alharfoush, E., Tomé, Â. R., et al. (2020). Role of Adenosine in Epilepsy and Seizures. J. Caffeine Adenosine Res. 10 (2), 45-60. doi:10.1089/caff.2019.0022

Titman, P., Pink, E., Skucek, E., O’Hanlon, K., Cole, T. J., Gaspar, J., et al. (2008). Cognitive and Behavioral Abnormalities in Children after Hematopoietic Stem Cell Transplantation for Severe Congenital Immunodeficiencies. Blood 112 (9), 3907-3913. doi:10.1182/blood-2008-04-151332

Tkacz-Stachowska, K., Lechward, K., and Skladanowski, A. C. (2005). Isolation and Characterization of Pigeon Breast Muscle Cytosolic 5'-Nucleotidase-I (cN-I). Acta Biochim. Pol. 52 (4), 789-796. doi:10.18388/abp.2005_3390

Toczek, M., Pierzynowska, K., Kutryb-Zajac, B., Gaffke, L., Slominska, E. M., Wegrzyn, G., et al. (2018). Characterization of Adenine Nucleotide Metabolism in the Cellular Model of Huntington's Disease. Nucleosides, Nucleotides and Nucleic Acids 37 (11), 630-638. doi:10.1080/15257770.2018.1481508

Tomczyk, M., Glaser, T., Ulrich, H., Slominska, E. M., and Smolenski, R. T. (2020). Huntingtin Protein Maintains Balanced Energetics in Mouse Cardiomyocytes. Nucleosides, Nucleotides \& Nucleic Acids, 1-8. doi:10.1080/15257770.2020.1815769

Torres, Á., Erices, J. I., Sanchez, F., Ehrenfeld, P., Turchi, L., Virolle, T., et al. (2019). Extracellular Adenosine Promotes Cell Migration/invasion of Glioblastoma Stem-like Cells through A3 Adenosine Receptor Activation under Hypoxia. Cancer Lett. 446, 112-122. doi:10.1016/j.canlet.2019.01.004

Torres, A., Vargas, Y., Uribe, D., Jaramillo, C., Gleisner, A., Salazar-Onfray, F., et al. (2016). Adenosine A3 Receptor Elicits Chemoresistance Mediated by Multiple Resistance-Associated Protein-1 in Human Glioblastoma Stem-like Cells. Oncotarget 7 (41), 67373-67386. doi:10.18632/oncotarget.12033

Tozzi, M., Pesi, R., and Allegrini, S. (2013). On the Physiological Role of Cytosolic 5'-nucleotidase II (cN-II): Pathological and Therapeutical Implications. Cmc 20 (34), 4285-4291. doi:10.2174/0929867311320340007

Valdés, R., Javier Casado, F., and Pastor-Anglada, M. (2002). Cell-cycle-dependent Regulation of CNT1, a Concentrative Nucleoside Transporter Involved in the Uptake of Cell-cycle-dependent Nucleoside-Derived Anticancer Drugs. Biochem. Biophysical Res. Commun. 296 (3), 575-579. doi:10.1016/s0006291x (02)00919-1

Vijayan, D., Young, A., Teng, M. W. L., and Smyth, M. J. (2017). Targeting Immunosuppressive Adenosine in Cancer. Nat. Rev. Cancer 17 (12), 709-724. doi:10.1038/nrc.2017.86

Vincenzi, F., Corciulo, C., Targa, M., Casetta, I., Gentile, M., Granieri, E., et al. (2013). A2Aadenosine Receptors Are Up-Regulated in Lymphocytes from Amyotrophic
Lateral Sclerosis Patients. Amyotroph. Lateral Scler. Frontotemporal Degeneration 14 (5-6), 406-413. doi:10.3109/21678421.2013.793358

Vincenzi, F., Pasquini, S., Borea, P. A., and Varani, K. (2020). Targeting Adenosine Receptors: A Potential Pharmacological Avenue for Acute and Chronic Pain. Ijms 21 (22), 8710. doi:10.3390/ijms21228710

Wall, M. J., Atterbury, A., and Dale, N. (2007). Control of Basal Extracellular Adenosine Concentration in Rat Cerebellum. J. Physiol. 582 (Pt 1), 137-151. doi:10.1113/jphysiol.2007.132050

Walldén, K., and Nordlund, P. (2011). Structural Basis for the Allosteric Regulation and Substrate Recognition of Human Cytosolic $5^{\prime}$-Nucleotidase II. J. Mol. Biol. 408, 684-696. doi:10.1016/j.jmb.2011.02.059

Wang, Y., Zhao, J., Guo, F.-L., Gao, X., Xie, X., Liu, S., et al. (2020). Metformin Ameliorates Synaptic Defects in a Mouse Model of AD by Inhibiting Cdk5 Activity. Front. Cell. Neurosci. 14, 170. doi:10.3389/fncel.2020.00170

Watanabe, K., Stringer, S., Frei, O., Umićević Mirkov, M., de Leeuw, C., Polderman, T. J. C., et al. (2019). A Global Overview of Pleiotropy and Genetic Architecture in Complex Traits. Nat. Genet. 51 (9), 1339-1348. doi:10.1038/s41588-0190481-0

Wennberg, A. M. V., Hagen, C. E., Edwards, K., Roberts, R. O., Machulda, M. M., Knopman, D. S., et al. (2018). Association of Antidiabetic Medication Use, Cognitive Decline, and Risk of Cognitive Impairment in Older People with Type 2 Diabetes: Results from the Population-Based Mayo Clinic Study of Aging. Int. J. Geriatr. Psychiatry 33 (8), 1114-1120. doi:10.1002/gps.4900

Whitmore, K. V., and Gaspar, H. B. (2016). Adenosine Deaminase Deficiency More Than Just an Immunodeficiency. Front. Immunol. 7, 314. doi:10.3389/ fimmu.2016.00314

Williams, T., Courchet, J., Viollet, B., Brenman, J. E., and Polleux, F. (2011). AMPactivated Protein Kinase (AMPK) Activity Is Not Required for Neuronal Development but Regulates Axogenesis during Metabolic Stress. Proc. Natl. Acad. Sci. 108 (14), 5849-5854. doi:10.1073/pnas.1013660108

Williams-Karnesky, R. L., Sandau, U. S., Lusardi, T. A., Lytle, N. K., Farrell, J. M., Pritchard, E. M., et al. (2013). Epigenetic Changes Induced by Adenosine Augmentation Therapy Prevent Epileptogenesis. J. Clin. Invest. 123 (8), 3552-3563. doi:10.1172/JCI65636

Williams-Karnesky, R., and Stenzel-Poore, M. (2009). Adenosine and Stroke: Maximizing the Therapeutic Potential of Adenosine as a Prophylactic and Acute Neuroprotectant. Curr. Neuropharmacol. 7 (3), 217-227. doi:10.2174/ 157015909789152209

Xu, S., Shao, Q.-Q., Sun, J.-T., Yang, N., Xie, Q., Wang, D.-H., et al. (2013). Synergy between the Ectoenzymes CD39 and CD73 Contributes to Adenosinergic Immunosuppression in Human Malignant Gliomas. Neuro Oncol. 15 (9), 1160-1172. doi:10.1093/neuonc/not067

Xu, X., Negandhi, J., Min, W., Tsui, M., Post, M., Harrison, R. V., et al. (2019). Early Enzyme Replacement Therapy Improves Hearing and Immune Defects in Adenosine Deaminase Deficient-Mice. Front. Immunol. 10, 416. doi:10.3389/ fimmu.2019.00416

Xu, Z., Xu, P., Chen, Y., Liu, J., Zhang, Y., Lv, Y., et al. (2015). ENT1 Inhibition Attenuates Epileptic Seizure Severity via Regulation of Glutamatergic Neurotransmission. Neuromol Med. 17 (1), 1-11. doi:10.1007/s12017-0148338-2

Yang, W., Zhou, X., Zimmermann, H. R., and Ma, T. (2020). Brain-specific Suppression of AMPKa2 Isoform Impairs Cognition and Hippocampal LTP by PERK-Mediated eIF2a Phosphorylation. Mol. Psychiatry. doi:10.1038/ s41380-020-0739-Z

Yao, S. Y. M., Ng, A. M. L., Vickers, M. F., Sundaram, M., Cass, C. E., Baldwin, S. A., et al. (2002). Functional and Molecular Characterization of Nucleobase Transport by Recombinant Human and Rat Equilibrative Nucleoside Transporters 1 and 2. J. Biol. Chem. 277 (28), 24938-24948. doi:10.1074/jbc.M200966200

Yee, B. K., Singer, P., Chen, J.-F., Feldon, J., and Boison, D. (2007). Transgenic Overexpression of Adenosine Kinase in Brain Leads to Multiple Learning Impairments and Altered Sensitivity to Psychomimetic Drugs. Eur. J. Neurosci. 26 (11), 3237-3252. doi:10.1111/j.1460-9568.2007.05897.x

Yun, Y. C., Jeong, S. G., Kim, S. H., and Cho, G. W. (2019). Reduced Sirtuin 1/ adenosine Monophosphate-activated Protein Kinase in Amyotrophic Lateral Sclerosis Patient-derived Mesenchymal Stem Cells Can Be Restored by Resveratrol. J. Tissue Eng. Regen. Med. 13 (1), 110-115. doi:10.1002/term.2776 Zamzow, C. R., Bose, R., and Parkinson, F. E. (2009). N-methyl-d-aspartate-evoked Adenosine and Inosine Release from Neurons Requires Extracellular 
calciumThis Article Is One of a Selection of Papers Published in a Special Issue Celebrating the 125th Anniversary of the Faculty of Medicine at the University of Manitoba. Can. J. Physiol. Pharmacol. 87 (10), 850-858. doi:10.1139/Y09-075

Zervou, M., Goulielmos, G., Matalliotakis, M., Matalliotaki, C., Spandidos, D., and Eliopoulos, E. (2020). Role of Adenosine Deaminase 2 Gene Variants in Pediatric Deficiency of Adenosine Deaminase 2: A Structural Biological Approach. Mol. Med. Rep. 21 (2), 876-882. doi:10.3892/mmr. 2019.10862

Zhang, L., Ou, J., Xu, X., Peng, Y., Guo, H., Pan, Y., et al. (2015). AMPD1 Functional Variants Associated with Autism in Han Chinese Population. Eur. Arch. Psychiatry Clin. Neurosci. 265 (6), 511-517. doi:10.1007/s00406-014-0524-6

Zhang, Y., Cao, H., Qiu, X., Xu, D., Chen, Y., Barnes, G. N., et al. (2020). Neuroprotective Effects of Adenosine A1 Receptor Signaling on Cognitive Impairment Induced by Chronic Intermittent Hypoxia in Mice. Front. Cell. Neurosci. 14, 202. doi:10.3389/fncel.2020.00202

Zhao, Z., Sui, Y., Gao, W., Cai, B., and Fan, D. (2015). Effects of Diet on Adenosine Monophosphate-Activated Protein Kinase Activity and Disease Progression in an Amyotrophic Lateral Sclerosis Model. J. Int. Med. Res. 43 (1), 67-79. doi:10. 1177/0300060514554725

Zhou, M., Duan, H., Engel, K., Xia, L., and Wang, J. (2010). Adenosine Transport by Plasma Membrane Monoamine Transporter: Reinvestigation and Comparison with Organic Cations. Drug Metab. Dispos 38 (10), 1798-1805. doi:10.1124/dmd.110.032987

Zhou, Q., Yang, D., Ombrello, A. K., Zavialov, A. V., Toro, C., Zavialov, A. V., et al. (2014). Early-onset Stroke and Vasculopathy Associated with Mutations in ADA2. N. Engl. J. Med. 370 (10), 911-920. doi:10.1056/NEJMoa1307361

Zhou, X., Chen, Q., Huang, H., Zhang, J., Wang, J., Chen, Y., et al. (2020). Inhibition of P38 MAPK Regulates Epileptic Severity by Decreasing Expression
Levels of A1R and ENT1. Mol. Med. Rep. 22 (6), 5348-5357. doi:10.3892/mmr. 2020.11614

Zhu, C., Chrifi, I., Mustafa, D., van der Weiden, M., Leenen, P. J. M., Duncker, D. J., et al. (2017a). CECR1-mediated Cross Talk between Macrophages and Vascular Mural Cells Promotes Neovascularization in Malignant Glioma. Oncogene 36 (38), 5356-5368. doi:10.1038/onc.2017.145

Zhu, C., Mustafa, D., Zheng, P.-p., van der Weiden, M., Sacchetti, A., Brandt, M., et al. (2017b). Activation of CECR1 in M2-like TAMs Promotes Paracrine Stimulation-Mediated Glial Tumor Progression. Neuonc 19 (5), now251-659. doi:10.1093/neuonc/now251

Zimmermann, H. (1992). 5'-Nucleotidase: Molecular Structure and Functional Aspects. Biochem. J. 285 (Pt 2), 345-365. doi:10.1042/bj2850345

Zimmermann, H. R., Yang, W., Kasica, N. P., Zhou, X., Wang, X., Beckelman, B. C., et al. (2020). Brain-specific Repression of AMPKal Alleviates Pathophysiology in Alzheimer's Model Mice. J. Clin. Invest. 130 (7), 3511-3527. doi:10.1172/ JCI133982

Conflict of Interest: The authors declare that the research was conducted in the absence of any commercial or financial relationships that could be construed as a potential conflict of interest.

Copyright (C) 2021 Garcia-Gil, Camici, Allegrini, Pesi and Tozzi. This is an openaccess article distributed under the terms of the Creative Commons Attribution License (CC BY). The use, distribution or reproduction in other forums is permitted, provided the original author(s) and the copyright owner(s) are credited and that the original publication in this journal is cited, in accordance with accepted academic practice. No use, distribution or reproduction is permitted which does not comply with these terms. 


\section{GLOSSARY}

AD: Alzheimer's disease

ADA: adenosine deaminase

ADF: astrocytoma cell line

ADK: adenosine kinase

$\mathrm{ADK}_{\mathrm{L}}$ : ADK-long

ADKs: ADK-short

ALS: amyotrophic lateral sclerosis

AMPD: AMP deaminase

AMPK: AMP-activated protein kinase

C9orf72: chromosome 9 open reading frame 72

CD26: dipeptidyl peptidase- 4

CD39: ectonucleoside triphosphate diphosphohydrolase

CD73: ecto-5' - nucleotidase

CNT1-3: concentrative nucleoside transporter 1-3

dATP: deoxyadenosine triphosphate

ENT1-4: equilibrative nucleoside transporters 1-4

FUS: fused in sarcoma

GRP58: glucose-regulated protein 58
GSCs: glioblastoma stem-like cells

HD: Huntington's disease

HPRT: hypoxanthine-guanine phosphoribosyltransferase

HSP: hereditary spastic paraplegia

HTT: huntingtin

IMP: inosine monophosphate

iPSCs: induced pluripotent stem cells

NBTI: nitrobenzythioinosine

NT5C1: cytosolic 5'-nucleotidase I

NT5C2: cytosolic 5'-nucleotidase II

PD: Parkinson's disease

PNP: purine nucleoside phosphorylase

PRPP: 5-phosphoribosyl-1-pyrophosphate

SAH: S-adenosyl homocysteine

SAHH: S-adenosyl homocysteine hydrolase

SAM: S-adenosylmethionine

SCID: severe combined immunodeficiency

SOD1: superoxide dismutase 1

TARDBP: TAR DNA binding protein 